\title{
Avaliação da resposta linfoproliferativa de pacientes com paracoccidioidomicose e indivíduos curados a antígenos de Paracoccidioides brasiliensis: filtrado de cultura, gp43 e gp43 tratada com metaperiodato
}

Dissertação apresentada ao Departamento de Dermatologia da Faculdade de Medicina da Universidade de São Paulo para obtenção do título de Mestre em Ciências

Área de concentração: Dermatologia

Orientador: Prof. Dr. Alberto J. da Silva Duarte 


\section{Avaliação da resposta linfoproliferativa de pacientes com paracoccidioidomicose e indivíduos curados a antígenos de Paracoccidioides brasiliensis: filtrado de cultura, gp43 e gp43 tratada com metaperiodato}

Dissertação apresentada ao Departamento de Dermatologia da Faculdade de Medicina da Universidade de São Paulo para obtenção do título de Mestre em Ciências

Área de concentração: Dermatologia Orientador: Prof. Dr. Alberto J. da Silva Duarte 
Dedico esta dissertação aos meus pais e ao meu noivo, sem eles eu jamais teria forças para continuar e terminar este trabalho 


\section{AGRADECIMENTOS}

Primeiramente agradeço a Deus por todas as benfeitorias em minha vida e por estar sempre em meu coração.

Quero agradecer imensamente aos meus pais Roberto Ogusuku e Helena Iko Suzuki Ogusuku e ao meu irmão Ricardo Ogusuku, por sempre acreditarem em mim, pelo apoio, carinho e compreensão e por nunca desistirem. Amo vocês! Minhas preciosidades, meus amores......

Ao meu querido noivo Eduardo Rafael Ramos Ferraz, pela paciência nos meus momentos ruins, pelo carinho e pela cumplicidade, mas principalmente por ser este homem maravilhoso que sempre está ao meu lado independente da situação. Amo-te muito!!!

Ao Gil Benard, por me "adotar", por acreditar em mim e dividir toda sua experiência profissional.

A minha querida amiga Camila Rodrigues Cacere, por me auxiliar na execução, finalização e revisão deste trabalho.

Ao querido amigo Nelson, que sempre esteve ao meu lado levantando meu astral nas horas difíceis e sempre com calma mostrando o lado positivo da vida.

As minhas grandes amigas e colegas de trabalho Noemia Orii, Rosangela Maria Araújo e Bianca, pela paciência, carinho e conselhos, mas principalmente pela linda amizade.

Aos amigos do grupo de "PB" e "TB": Heide Baida, Leia Rodrigues, Guilherme Silveira e Vanessa Batista, por dividirem comigo seus conhecimentos e experiências profissionais. Adoro vocês. 
Ao André Goto e Marcio pelo suporte na configuração deste trabalho e suporte na parte de informática.

A todos os integrantes dos grupos de "Imunodeficiência, Experimental, Citometria, Genotipagem, Carga Viral, Complemento, HIV e HTLV” e aos funcionários do LIM-56 que de alguma forma, direta ou indiretamente, me auxiliaram no término desta dissertação.

Ao Prof. Dr. Alberto José da Silva Duarte por abrir as portas do laboratório para a realização deste trabalho.

E finalmente, os pacientes do Hospital das Clínicas da Faculdade de Medicina da Universidade de São Paulo e Instituto de Infectologia Emilio Ribas e voluntários que participaram deste estudo.

\section{Obrigada por tudo!!!!}




\section{$\underline{\text { Sumário }}$}

Lista de abreviaturas

Lista de Figuras e gráficos

Resumo

Summary

$\begin{array}{ll}\text { 1- Introdução } & 01\end{array}$

2- Justificativa 13

3- Objetivo 14

4- Materiais e Métodos 15

4.1- Casuística 15

4.2- Obtenção do antígeno de P. brasiliensis 17

4.3- Obtenção de células mononucleares de sangue periférico de 18

paciente, controles curados e indivíduos não expostos ao fungo para

avaliação da resposta linfoproliferativa

4.4- Ensaios de ELISA para IL-12, IFN- $\gamma$ e IL-4 19

4.5- Ensaio de ELISA para IL-10 20

4.6- Análise estatística 20

5- Resultados 21

6- Discussão 32

7- Conclusões

8- Referências Bibliográficas $\quad 38$ 
PCM

CIE

CMA

$\mathrm{CMN}$

CNS

ELISA

et al.

Filtrado

Gp160

Gp43

Gp70

$\mathrm{H}_{2} \mathrm{SO}_{4}$

HST

ID

IFN- $\gamma$

IL- 10

IL- 12

IL- 2

IL- 4

IL- 5

Meta

$\mathrm{PbAg}$
Paracoccidioidomicose

Contraimunoeletroforese

Candida Metabolic Antigen

Células mononucleares

Conselho Nacional de Saúde

Enzyme-linked immunosorbent assay

E outros

Filtrado de cultura livre de gp43

Glicoproteína de 160KDa

Glicoproteína de 43KDa

Glicoproteína de 70KDa

Ácido Sulfúrico

Teste de hipersensibilidade cutânea tardia

Imunodifusão dupla

Interferon Gama

Interleucina 10

Interleucina 12

Interleucina 2

Interleucina 4

Interleucina 5

Gp43 tratada com metaperidato

Antígeno bruto de $P$. brasiliensis 
PHA

PWM

TGF- $\beta$

TNF- $\alpha$
Phytohemaglutinina

Mitógeno Pokeweed

Transforming growth factor beta

Fator de necrose tumoral alfa 


\section{LISTA DE FIGURAS E GRÁFICOS}

Figura 1 Foto do P. brasiliensis na forma de levedura

Tabela 1 Sorologia de ID e CIE de indivíduos com a doença ativa

Figura 2 Gel demonstrando as bandas de gp43, da gp43 tratada com metaperiodato e filtrado de cultura e o filtrado de cultura livre de gp43

Gráfico 1 Avaliação da resposta linfoproliferativa em indivíduos curados de PCM para avaliação da concentração de uso do filtrado de cultura

Gráfico 2 Avaliação da resposta linfoproliferativa em indivíduos curados de PCM para avaliação da concentração de uso da gp43 metaperiodatada.

Gráfico 3 Linfoproliferação do grupo controle de indivíudos sadios com os diferentes antígenos do P. brasiliensis - filtrado de cultura sem gp43 (FILT), gp43 tratada com metaperiodato (MET) e gp43 (gp43) e antígenos de pokeweed (PWM) como controle positivo e antígeno de Candica albicans (CMA) como controle de antígeno fúngico 
Gráfico 4 Linfoproliferação do grupo controle de indivíduos curados de

PCM com os diferentes antígenos derivados do P. brasiliensis

Gráfico 5 Linfoproliferação do grupo de individuos com a doença ativa com os diferentes antígenos derivados do P. brasiliensis

Gráfico 6 Detecção de IL-12 em sobrenadantes de cultura de células coletadas após $18 \mathrm{hs}$ de estímulo com antígeno de Candida albicans (CMA), gp43 de P. brasiliensis, filtrado de cultura sem gp43 (filtrado) e gp43 tratada com metaperiodato (meta).

Gráfico 7 Detecção de IFN- $\gamma$ em sobrenadantes de cultura de células coletados após 72 hs de estímulo com antígeno metabólico de Candida albicans (CMA), gp43 de $P$. brasiliensis, filtrado de cultura sem gp43 (filtrado) e gp43 tratada com metaperiodato (meta).

Gráfico 8 Detecção de IL-10 em sobrenadantes de cultura de células coletados após 18 hs de estímulo com antígeno metabólico de Candida albicans (CMA), gp43 de P. brasiliensis, filtrado de cultura sem gp43 (filtrado) e gp43 metaperiodatada (meta). 
RESUMO

A Paracoccidioidomicose é micose sistêmica causada pelo fungo Paracoccidioides brasiliensis, endêmico na América Latina, especialmente Brasil. Para melhor avaliarmos a resposta imune celular frente a diferentes componentes do fungo, como gp43, considerada o antígeno imunodominante de $P$. brasiliensis, filtrado de cultura livre de gp43 (Filtrado), e gp43 tratada com metaperiodato (meta), utilizamos os ensaios de linfoproliferação e ELISA para detecção das citocinas IL-4, IL-10, IL-12 e IFN- $\gamma$. Os resultados com relação à gp43 corroboram dados da literatura e de nosso laboratório demonstrando que gp43 é o antígeno imunodominante do fungo e pode estar envolvido no mecanismo de anergia dos linfócitos $\mathrm{T}$ de pacientes com a micose ativa. Com o Filtrado observamos respostas linfoproliferativas positivas, porém menores que com gp43, também evidenciando a anergia de linfócitos T de pacientes, e a indução de IL-10 em células de controles curados, podendo representar assim um mecanismo de imunossupressão. Com relação à meta, esta não induziu resposta linfoproliferativa nem a síntese de citocinas, sugerindo não ser um antígeno apropriado para esse tipo de avaliação.

Descritores: 1- Citocinas; 2- Paracoccidioidomicose; 3- Imunidade Celular; 4Linfócitos T; 5- Antígenos. 


\section{SUMMARY}

Paracoccidioidomycosis is a systemic mycosis caused by Paracoccidioides brasiliensis, endemic in latin América, specially Brazil. To better understand the cellular immune responses to different components of the yeast, such as gp43, considered the immunodominant antigen, a culture filtrate free of gp43 (CF), and gp43 treated with metaperiodate, we used lymphoproliferative assays and ELISA to detect the cytokines IL-4, IL-10, IL-12 e IFN- $\gamma$. The results with gp43 were consistent with the literature and previous with data from our Laboratory showing that gp43 is the immunodominant antigen of $P$. brasiliensis and is likely involved with the anergy of T-cells from patients. With CF we observed positive, but weaker, proliferative responses. It also evidenced the T-cell anergy of patients and the preferential induction of IL-10 in cells from cured controls. The latter can represent a mechanism of anergy induction. With meta, we observed that neither induce proliferative responses nor cytokine secretion, being apparently an inappropriate antigen for use in cellular immunoassays.

Descriptors: 1 - Cytokines; 2 - Paracoccidioidomycosis; 3 - Cellular Immunity; 4 Lymphocytes; 5 - Antigens. 


\section{1-INTRODUCÃ̃}

A Paracoccidioidomicose (PCM) é uma doença sistêmica causada pelo fungo dimórfico Paracoccidioides brasiliensis que ocorre endemicamente em várias regiões da América Latina, onde o Brasil, a Venezuela, a Colômbia e a Argentina são os países com maior freqüência de casos. No Brasil o Paracoccidioides brasiliensis é encontrado em quase todas as regiões (Sul, Sudeste, Centro-Oeste e Norte) sendo encontrados poucos relatos no Nordeste. A doença também tem sido diagnosticada em outros países fora da América latina, mas em todas as ocasiões os pacientes apresentavam histórico de passagem ou moradia em países endêmicos. GINARTE et al. (2003), por exemplo, relataram 3 casos alóctones de pacientes com PCM na Espanha. O Brasil é o país que possui o maior número de casos da doença, sendo a oitava causa de mortalidade por doença predominantemente crônica ou repetitiva, entre as infecciosas e as parasitárias, e a mais elevada taxa de mortalidade entre as micoses sistêmicas, porém a paracoccidioidomicose não é de notificação compulsória, sendo sua real prevalência ainda desconhecida, no entanto, estima-se que a taxa anual de incidência entre a população brasileira seja de 1-3/100.000 habitantes e a de mortalidade de 0,14/100.000 habitantes e em regiões endêmicas, essa estimativa está em torno de 10 milhões de pessoas infectadas, no qual a maioria não apresente sintomas clínicos. (BARBOSA et al. 1982; LACAZ. In DEL NEGRO et al. 1982; COUTINHO et al. 2002; CALLE et al. 2001, RESTREPO. 1985; SAN-BLAS et al. 2002; RESTREPO et al. 2001; ALMEIDA et al. 2003; MARQUES et al. 1983).

A doença foi descrita pela primeira vez por ADOLPHO LUTZ, em 1908, em 2 pacientes internados na Santa Casa de Misericórdia. Publicou suas observações no "Brazil Médico" (revista editada no Rio de Janeiro) em $1^{\circ}$ de Abril do mesmo ano, descreveu o 
fungo em cultivo como "semelhante à pela de um ratinho branco" e considerou-o diferente do Coccidioides immitis descrito por POSADAS e WERNICKE em 1892 na Argentina. Em 1912 ALFONSO SPLENDORE começa a estudar a doença e a enquadra em um gênero já conhecido em micologia - Zymonema ficando o agente como Zymonema brasiliensis. Novos casos foram aparecendo e muitos trabalhos foram publicados, a doença passa a ser denominada de "Blastomicose brasileira", mas logo muda para "Blastomicose SulAmericana" devido às observações de casos em outros países da América do Sul. Muitos nomes foram dados à doença como "granuloma paracoccidióico, granulomatose paracoccidióidica, granuloma ganglionar maligno de origem blastomicélica, granulomatose blastomicóide neotropical, adenomicose, doença de Lutz, doença de Lutz-SplendoreAlmeida..” Em 1930, ALMEIDA estudou a biologia e morfologia do parasita, criando um novo gênero de acordo com as regras estabelecidas por Linneu, sendo então o agente conhecido como Paracoccidioides brasiliensis. (LACAZ. 1908; LUTZ. 1908; LACAZ. 2002; LUTZ. 1908; LACAZ. 1949; ALMEIDA. 1930; LACAZ. In DEL NEGRO et al. 1982)

Segundo SAN-BLAS et al (2002) e BIALEK et al (2000) o fungo possui a seguinte taxonomia: REINO: Fungi

FILO ou DIVISÃO: Ascomycota

CLASSE: Pleomycetes

ORDEM: Onyganales

FAMÍLIA: Onygenaceae

GÊNERO: Paracoccidioides

ESPÉCIE: brasiliensis 
Em 1961, MOSES estuda a reação de fixação do complemento para $P$. brasiliensis e no mesmo ano, FERRI utiliza a técnica de imunodifusão dupla (ID) para diagnóstico da paracoccidioidomicose. AGUIAR PUPO em 1965 e GONZÁLEZ-OCHOA em 1972 estabeleceram o conceito de que a porta de entrada do parasito era por inalação das formas infectantes do fungo. Em 1977 e 1979 FELIPE e GIOCONDA SAN-BLAS relacionaram a virulência do parasito com a presença de $\alpha-1-3$-glucana na parede celular do fungo enquanto que mutantes com $\alpha$-manana perdem seu poder patogênico, além disso, sugeriram também que a $\alpha$-1-3-glucana estaria envolvida na proteção do fungo contra enzimas digestivas produzidas pelos leucócitos e macrófagos do hospedeiro. Somente após muitos estudos FAVA NETTO pode padronizar um antígeno polissacarídeo que permitiu a padronização da reação de fixação do complemento e de uma reação de precipitação em tubos utilizado para o diagnóstico, o prognóstico e o controle de cura da doença além de grandes avanços para os estudos imunológicos (ALMEIDA, 1930; BARBOSA et al. 1982; LACAZ. In DEL NEGRO et al. 1982; BUENO et al. 1997)

Paracoccidioides brasiliensis possui glicoproteínas, glicopeptídeos, lipídeos e polissacarídeos, sendo capaz de hidrolisar a uréia; possui antígenos comuns com Blastomyces dermatitidis, Paracoccidioides loboi e Histoplasma capsulatum. P. brasiliensis é dotado de completa estrutura antigênica, revelada através de reações de imunoeletroforese, principalmente face a soros hiperimunes, com a demonstração do arco "E" de migração catódica, possuindo atividades de fosfatase alcalina identificado pela primeira vez por YARZÁBAL em 1971. (LACAZ In DEL NEGRO et al. 1982; SAN-BLAS et al. 1977; SAN-BLAS et al. 1982; YARZÁBAL et al. 1978)

RESTREPO e MONCADA (1974) e NEGRONI (1976), utilizaram a difusão em gel de ágar e a imuno-eletroforese, onde foi demonstrado a presença do arco "E" de Yarzábal 
(1977), com migração catódica e que corresponde aos arcos "A" de RESTREPO e DROUHET (1970) e "L" de CONTI-DIAZ et al (1973) e CAMPO-AASEN et al (1980) destacando o antígeno " $\mathrm{E}_{2}$ " por técnica histo-imuno-enzimática, em células leveduriforme do P. brasiliensis.

A parede celular do fungo foi separada em 3 frações: fração 1 - Álcali insolúvel, fração 2 - álcali solúveis precipitadas por ácido acético e fração 3 - álcali solúveis não precipitadas por ácido acético. As frações 1 e 2 demonstram fibrilos e em estudos bioquímicos demonstrou que a fração 1 é continuada por quitina e $\beta$-1-3-glucan e a fração 2 por $\alpha$-1-3-glucan (CARBONELL et al, 1970; KANETSUNA \& CARBONELL 1970)

O P. brasiliensis é um fungo dimórfico que depende da temperatura para a expressão da sua morfologia, podendo ser leveduriforme ou micelial. A fase levefuriforme (ou de levedura) é marcada por possuir formas arredondadas ou ovais, com dupla membrana, com ou sem gêmulas, podendo atingir de 5 a $25 \mu \mathrm{m}$ (figura 1), além disso, a levedura é a forma parasitária e tem seu cultivo e reprodução a $35^{\circ}-37^{\circ}$ C. Já a forma micelial ou fase filamentosa, cresce em temperatura ambiente, tem filamentos brancos de hifas aéreas muito curtas, com aspecto cotonoso, septado e sem conídios (BARBOSA et al. 1982; LACAZ In DEL NEGRO et al. 1982; KUROKAWA et al. 1998; RESTREPO. 1985; LACAZ In FRANCO et al. 1994; RESTREPO et al. 1983). 


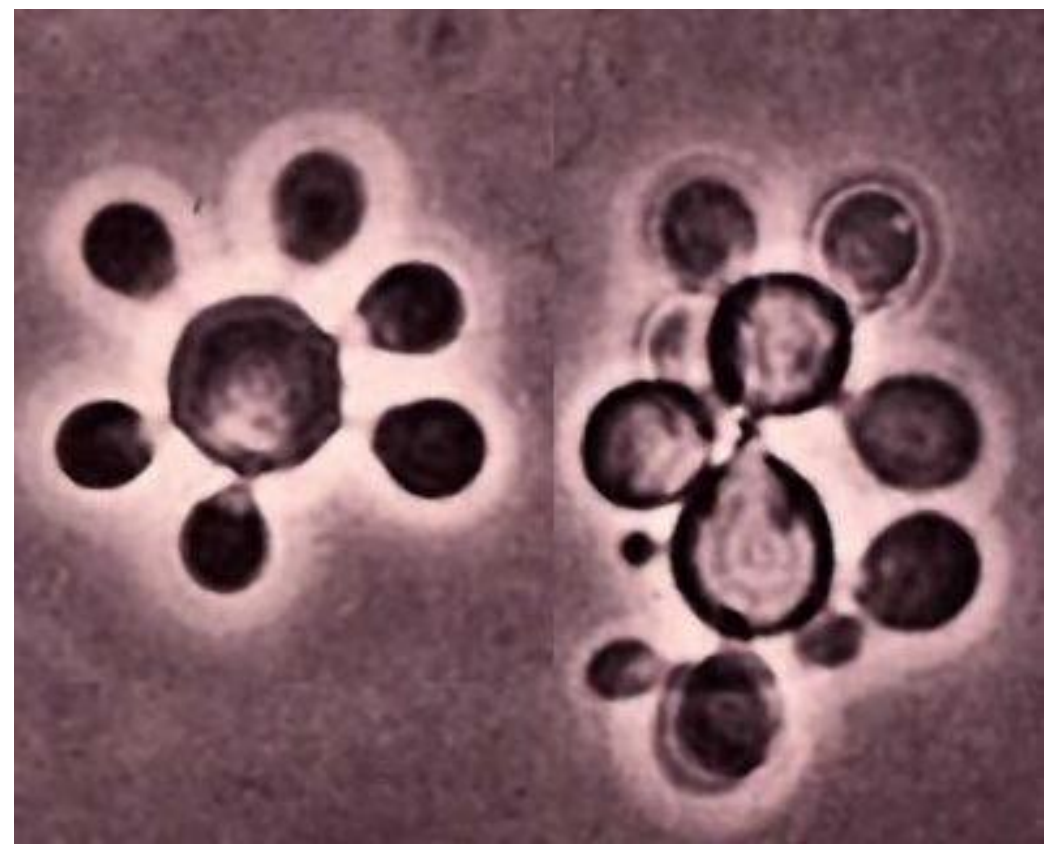

Figura 1: Paracoccidioides brasiliensis na forma de levedura. Foto retirada do site: botit.botany.wisc.edu/toms_fungi/jan2005.html

O P. brasiliensis já foi isolado do solo por NEGRONI et al. (1966) na Argentina, e por ALBORNOZ et al. (1971) na Venezuela. No Brasil o fungo foi isolado do solo por SHOME et al (1963) e TERÇARIOLI et al (2007). FERREIRA et al. (1990) e GARCIA et al. (1993) encontraram isolados do fungo em ração de cães e vegetais que estavam contaminados com o solo. O P. brasiliensis também foi isolado em fezes de pingüins (Pygoscelis adeliae) na Antártica, GUEZELLE et al. (1989), em fezes de morcegos (Artibeus lituratus), e em tatus apenas na espécie Dasypus novemcinctus, sendo possível reservatório do agente $P$. brasieliensis. Já outros gêneros e espécies de tatus como, por exemplo: D. septemcintus, $D$. kapplari e Euphractus sexcinctus, que possuem hábitos semelhantes ao D. novemcinctus, não obtiveram resultados positivos. (BAGAGLI et al. 1998; SILVA-VERGARA et al. 2000; FERREIRA et al. 1990; GROSSE et al. 1965; NAIFF et al. 1989; NAIFF et al. 1986; 
FRANCO et al. 2000; HELDER et al. 2003; SILVA-VERGARA et al. 1999; SILVAVERGARA et al. 1998).

Estudos experimentais revelaram que a cobaia, o hamster, o rato, o camundongo e o cão são sensíveis á infecção. Recentemente foram relatados casos da doença em cães, porém a cultura fúngica só foi obtida em um único caso. A presença de anticorpos anti-gp43 foram testadas em soros de 305 cães das regiões urbanas, periurbanas e rural de Londrina, utilizando o método de ELISA, e foi observada uma positividade de 14\%, 48,8\% e 89,5\% respectivamente (ONO et al. 2003; RICCI et al. 2004; FAGUNDES. 2002; ONO et al. 2001).

ONO et al (2002) estudaram a interferência de produtos químicos utilizados na agricultura no desenvolvimento de $P$. brasiliensis e observaram que compostos químicos impediram o desenvolvimento in vitro de $P$. brasiliensis demonstrando parcialmente a dificuldade do isolamento do fungo a partir de amostras de solo (FRANCO et al. 2000)

O habitat natural do $P$. brasieliensis, ainda não está bem definido, mas vários estudos relatam sua prevalência em zonas rurais com temperaturas entre $10-28^{\circ} \mathrm{C}$, normalmente em regiões com invernos curtos, verões chuvosos e solo quase sempre ácido e áreas de solos de grande fertilidade, nos vales e nas proximidades de grandes rios apresentando elevado índice pluviométrico, entre 500-2.500mm/ano e dotados de vegetação abundante ou de extensas lavouras (BARBOSA et al. 1983; LONDERO In DEL NEGRO et al. 1982; RESTREPO et al. 1985; CADAVID et al. 1993; RESTREPO et al. 2001).

A doença é adquirida pela inalação de partículas ou propágulos infectantes do agente em sua forma micelial ou por implantação traumática cutânea ou mucosa e uma vez nos pulmões, sofre diferenciação para a forma de levedura ou forma infectante. (LONDERO et al. 1986; ALMEIDA et al. 2001; KUROKAWA et al. 1998; FRANCO. 1986; 
GONZÁLES-OCHOA. 1956; SAN-BLAS et al. 1984). Acomete indivíduos de ambos os sexos e várias faixas etárias, sendo mais raro em crianças (10 a 14 anos de idade), tendo apenas um relato da doença em uma criança de 2 anos de idade (PEREIRA et al. 2004; BLOTTA et al. 1999). Apesar da maior parte dos casos de paracoccidoioidomicose ocorrerem em trabalhadores rurais, cerca de $46 \%$ dos casos só na região de São Paulo, tendo maior prevalência em homens entre 41 e 50 anos.(BLOTTA et al. 1999). Há poucos casos documentados de ocorrência dessa micose entre índios brasileiros (FORJAZ et al. 1999). Segundo MARTINEZ et al. (2002), a maior prevalência de positividade para $P$. brasiliensis e H. capsulatum em estudo realizado na Reserva Indígena Xacriabá, em Minas Gerais, é entre as mulheres, podendo significar maior e mais duradoura resposta humoral frente ás infecções, além de maior exposição das mesmas aos fungos durante o trabalho agrícola, do qual participam muito ativamente.

Uma vez inalado, o fungo pode ser destruído no parênquima pulmonar por células fagocíticas ou multiplicar-se e produzir foco de infecção, o qual é drenado para o linfonodo regional. O indivíduo infectado, na maioria das vezes, consegue controlar a disseminação do fungo, permanecendo assintomático indefinidamente. O desenvolvimento de doença pode se dar de 2 formas. Raramente, semanas ou meses após a infecção inicial, os pacientes, em geral jovens de ambos os sexos, desenvolvem a forma aguda/sub-aguda ou juvenil, caracterizada pelo acometimento do sistema mononuclear fagocítico e pronunciada desregulação imunológica, manifestando-se principalmente por linfadenomegalias $(95,4 \%)$, hepatomegalia $(40 \%)$ e esplenomegalia $(23,1 \%)$. Entretanto, a maioria dos pacientes $(\geq$ 90\%) desenvolve manifestações clínicas relacionadas ao trato respiratório, anos ou décadas após a infecção inicial, a forma crônica ou do adulto, caracterizada por comportamento imunológico variável, afetando predominantemente homens adultos, em geral trabalhadores agrícolas. (BARBOSA et al. 1982; PANIAGO et al. 2003; TABORDA et al. 1998; 
ROMANO et al. 2002; BORGES-WALMSLEY et al. 2002; LOPEZ et al. 1983; LACAZ et al. 1959; LONDERO et al. 1986; FRANCO. 1986; MENDES In FRANCO et al. 1994; DEL NEGRO In FRANCO et al. 1994).

MARTINEZ et al (1992), sugeriu que o alcoolismo e a desnutrição estariam envolvidos na patogenia da doença, já que mais de 50\% dos pacientes de uma casuística de São Paulo ingeriam bebidas alcoólicas regularmente, e que a predisposição de alcoolistas adquirirem micoses profundas já havia sido observada em relação a candidíase, criptococose, esporotricose e aspergilose. Também foram realizados estudos mostrando a freqüência do tabagismo em cerca de $90,3 \%$ dos pacientes, em sua maioria com a forma aguda, estudados em Mato Grosso do Sul. (PANIAGO et al. 2003), e em cerca de 92,8\% dos pacientes estudados no Espírito Santo, com alto índice de alcoolismo $(68,3 \%)$. (SANTOS et al. 2003).

Do ponto de vista do sistema imune, a PCM é descrita como uma micose com graus variados de imunossupressão. Vários estudos observaram nítida correlação entre a gravidade da apresentação clínica e a intensidade das alterações da imunidade celular (MOTTA et al. 1935; Musatti et al.1976; PANUNTO-CASTELO et al. 2003; ROMANO et al. 2002; MENDES-GIANNINI et al. 2000; BLOTTA et al. 1993; FRANCO. 1987; FIGUEIREDO et al. 1986). Esta correlação clínico-imunológica também foi identificada em nosso laboratório. BENARD et. al (1996), estudaram in vitro a reatividade de linfócitos utilizando Phytohemaglutinina (PHA), mitógenos pokeweed (PWM), extrato antigênico de Candida albicans (CMA) e antígeno bruto, derivado da parede de Paracoccidioides brasiliensis $(\mathrm{PbAg})$ em pacientes com a forma aguda/subaguda e crônica da doença, antes, durante o tratamento e depois da cura clínica, além de indivíduos saudáveis respondedores ao $P$. brasiliensis, previamente tratados desta micose. Os resultados demonstraram que pacientes tanto com a forma aguda quanto com a forma crônica tiveram uma resposta muito baixa para 
o antígeno de $P$. brasiliensis quando comparados com os controles, porém os pacientes com a forma aguda da doença, considerada mais grave, tiveram níveis muito menores de resposta que os pacientes com a forma crônica. Após a cura clínica, a resposta linfoproliferativa desses pacientes se tornou similar à dos indivíduos controle. Neste mesmo estudo observaram em pacientes em tratamento a anergia ao teste intradérmico (teste de hipersensibilidade cutânea tardia - HST) para paracoccidioidina, altos níveis de anticorpos anti- $P$. brasiliensis, leucocitose e eosinofilia. Essas mudanças foram mais intensas em pacientes com a forma aguda da doença. Já após tratamento, o número de linfócitos totais, linfócitos T CD4+ e T CD8+ foram similares aos dos controles.

Paralelamente, KUROKAWA et al. (1998) demonstraram uma relação entre antigenemia e imunossupressão mediada por células em pacientes com paracoccidioidomicose e que in vitro, estudos demonstraram que o antígeno de $P$. brasiliensis tinha efeito supressor na resposta linfoproliferativa comparado com estímulo com Phytohemaglutinina (PHA).

Estudos posteriores em nosso laboratório (BENARD et al 2001) avaliaram a secreção de IL-2, IL-10 e IFN- $\gamma$ por células mononucleares de sangue periférico (PBMC) de pacientes com a forma aguda e a forma crônica da doença e indivíduos saudáveis sensibilizados ao $P$. brasiliensis e observaram que tanto as PBMC de pacientes com a forma aguda quanto com a forma crônica produziram baixos níveis de IL-2 e IFN- $\gamma$, mas níveis substancialmente altos de IL-10 quando estimulados com gp43. Entretanto, quando estimuladas com PHA essa secreção foi comparativamente mais alta nos três grupos confirmando a sugestão de trabalhos prévios de que o déficit imunológico na paracoccidioidmicose é predominantemente de natureza antígeno-específica. 
Segundo OLIVEIRA et al. (2002), indivíduos infectados caracterizam-se por ausência de anticorpos específicos, resposta linfoproliferativa vigorosa para antígeno de $P$. brasiliensis ( $\mathrm{PbAg}$ ), um padrão de citocinas típicas de resposta Th1, com produção de IFN- $\gamma$ e níveis basais de IL-4, IL-5 e IL-10, pacientes com a forma juvenil, possuem resposta linfoproliferativa para $\mathrm{PbAg}$ prejudicada, padrão de citocinas de resposta Th2, baixo nível da IFN- $\gamma$ e níveis de secreção significantemente mais altos de IL-4, IL-5 e IL-10, e pacientes com a forma adulta possuem resposta linfoproliferativa específica intermediária entre os indivíduos infectados e os pacientes com a forma juvenil, tendo altos níveis de secreção de IFN- $\gamma$ e IL-10, e baixo nível de IL-4 e IL-5.

CALICH et al. (1998), estudaram a imunoregulação em camundongos resistentes e susceptíveis pela dosagem de citocinas e demonstraram que animais resistentes produziam níveis de IFN- $\gamma$, IL-2 e citocinas do tipo Th2 (IL-4 e IL-5), precocemente, já os animais susceptíveis produziam baixos níveis de IFN- $\gamma$ e níveis significantes de IL-5 e IL-10 precocemente. Já macrófagos de camundongos B10, secretavam níveis elevados de TGF- $\beta$ e baixos de TNF- $\alpha$ e camundongos $\mathrm{A} / \mathrm{Sn}$ tinham altos níveis de TNF- $\alpha$ associados com baixos níveis de TGF- $\beta$, sugestionando que uma secreção precoce de altos níveis de TNF- $\alpha$ e IFN$\gamma$ seguido por uma sustentável secreção de IL-2 e IFN- $\gamma$ tem um papel dominante no mecanismo de resistência a infecção ao P.brasiliensis, e que secreção precoce de baixos níveis de TNF- $\alpha$ e IFN- $\gamma$ associados com produção de IL-5, IL-10 e TGF- $\beta$ caracterizam a doença progressiva e susceptibilidade do animal.

Entre os antígenos encontrados, destaca-se uma glicoproteína de $43 \mathrm{KDa}$ (gp43), que é a mais utilizada em modelos experimentais de PCM e muito estudada para fins diagnósticos (CALICH et al,1998, TABORDA et al, 1994, ALBUQUERQUE et al, 2005 ). Foi descrita pela primeira vez por YARZÁBAL et al. (1977), sendo um exoantígeno secretado pelo 
fungo na sua fase leveduriforme. PUCCIA et al. (1986) caracterizam quimicamente a gp43, e demonstraram a ausência de reação cruzada com outras micoses.

MENDES-GIANNINI et al. (1989), demonstraram que a gp43 é a glicoproteína mais comumente reconhecida pela maioria dos soros de pacientes com PCM, apresentando altos títulos de anticorpos.

Em nosso laboratório, BENARD et al. (1997) estudaram o reconhecimento da gp43 e da gp70 por linfócitos de indivíduos com PCM e indivíduos sensibilizados, tendo como resultado o maior reconhecimento para a gp43. Além disto, relataram a depressão da resposta proliferativa associada a altos níveis de anticorpos anti-gp43 para pacientes com a doença.

PANUTO-CASTELO et al. (2003) estudaram o reconhecimento por IgG de soro de pacientes com as diferentes formas clínicas da doença e relataram o grande reconhecimento da gp43, cerca de $100 \%$ para pacientes com a forma aguda, seguido de $95 \%$ para a gp160, e $65 \%$ para a gp70, já os pacientes com a forma crônica da doença tiveram cerca de $95 \%$ de reconhecimento para a gp43,60\% para a gp160 e 55\% para a gp 70, constatando assim ser a gp43 o antígeno mais importante no estudo de Paracoccidioides brasiliensis.

FERREIRA DA CRUZ et al. (1990), estudaram o isolamento e a antigenicidade da fração de $45 \mathrm{KDa}$ de $P$. brasiliensis e observaram que $90.6 \%$ dos soros de pacientes foram positivos e que não somente foi o componente imunodominante, mas também foi o antígeno mais específico para a resposta imune humoral.

Vários autores testaram a capacidade da gp43 tratada com metaperiodato em diferentes ensaios para imunodiagnóstico. Em reações de ELISA havia-se observado reatividade cruzada, provavelmente por alteração conformacional da molécula ao aderir à placa de Elisa, 
TABORDA et al. (1994) estudaram a gp43 e a gp43 tratada em ensaios de Dot Immunobinding como ferramenta de diagnóstico para PCM e relataram a ausência de falsos positivos e reações cruzadas com doenças como Jorge Lobo, Aspergilose, Candidíase e Criptococose, quando usada a gp43 tratada com metaperiodato, verificando uma alta sensibilidade e especificidade do ensaio. PUCCIA et al (1991) estudaram o papel do epitopo de carboidrato responsável pela reação cruzada nos ensaios de ELISA usando a gp43 e gp43 tratada. Observaram que as reações cruzadas com histoplasmose e doença de Jorge Lobo foram predominantemente atribuídas aos epitopos sensíveis a periotado contendo resíduos de galactose, porém após tratamento da gp43 obtiveram maior especificidade no teste.

ALBUQUERQUE et al (2005) também estudaram a gp43 tratada com metaperiodato para diagnóstico da PCM por ELISA. Estes autores utilizaram soros de pacientes adsorvidos contra soluções de antígenos de Candiada albicans ou Histoplasma capsulatum e diluições dos soros adicionadas de galactose, com a finalidade de se reduzir a reatividade cruzada. Entretanto, a especificidade máxima obtida neste estudo foi de $84 \%$, sugerindo que estes procedimentos foram insuficientes para eliminar todas as reações cruzadas. 


\section{2-JUSTIFICATIVA}

Tendo em vista que a gp43 é a molécula de $P$. brasiliensis melhor caracterizada e tem sido regularmente utilizada por nosso e outros grupos na avaliação da resposta imune celular de pacientes com PCM, por ser considerada antígeno imunodominante, tanto na resposta humoral como celular, nosso objetivo foi de:

a) confirmar sua importância primordial na resposta imune, analisando a capacidade de estimulação dos linfócitos por filtrado de cultura de $P$. brasiliensis, rico em componentes derivados do fungo, porém livre de gp43, e

b) verificar a importância de seu componente polissacarídico na resposta imune celular, utilizando gp43 tratada com metaperiodato que se mostrou imuno-reativa em estudos sorológicos realizados por outros grupos como ELISA e Dot Immunobinding. 


\section{3-OBJETIVO}

1) Avaliar a resposta linfoproliferativa de indivíduos com a doença ativa, indivíduos curados da doença e indivíduos sadios não expostos ao fungo, frente à gp43, ao como o filtrado de cultura livre de gp43 e a gp43 tratada com metaperiodato.

2) Avaliar a produção das citocinas IL-4, IL-10, IL-12 e IFN- $\gamma$ por células de indivíduos de diferentes grupos, quando estimuladas com a gp43, o filtrado livre de gp43 e a gp43 tratada com metaperiodato. 


\section{4-MATERIAIS E MÉTODOS}

\section{1-CASUÍSTICA}

Os pacientes com doença em atividade e os indivíduos curados foram encaminhados do Hospital das Clínicas da FMUSP e Instituto de Infectologia Emilio Ribas em colaboração do Dr. Gil Benard e Dra Luísa Batista

A coleta das amostras de sangue dos pacientes foi feita sempre que possível durante a punção venosa para a realização de avaliação sorológica e outros exames laboratoriais de rotina nos pacientes, após consentimento prévio do paciente, implicando em risco mínimo de acordo com a Resolução 196/96 do Conselho Nacional de Saúde (CNS). Foram coletados cerca de 10 - $20 \mathrm{~mL}$ de sangue heparinizado de cada paciente.

Foram estudados um total 48 indivíduos, sendo 12 pacientes com a doença ativa, previamente ao tratamento, 13 indivíduos controles sadios não expostos ao fungo (voluntários do laboratório LIM-56), e 23 indivíduos controles curados. Estes últimos são indivíduos saudáveis, já tratados de paracoccidioidomicose, com suspensão do tratamento há pelo menos 4 anos, sorologia anti- $P$. brasiliensis negativa (ou cicatriz sorológica), tendo sido recrutados do Hospital das Clínicas da FMUSP da mesma forma que em estudos prévios (BENARD et al, 1997, BENARD et al, 2001, CACERE et al, 2002, ROMANO et al, 2002, ROMANO et al, 2005). 


\begin{tabular}{|c|c|c|c|}
\hline Dorionter & \multicolumn{2}{|c|}{ Sorologia } & $C_{9}$ \\
\hline 1 & + & $1 / 64$ & M \\
\hline 2 & + & $1 / 512$ & M \\
\hline 3 & + & $1 / 64$ & M \\
\hline 4 & + & $1 / 8$ & $\mathrm{~F}$ \\
\hline 5 & + & $1 / 16$ & M \\
\hline 6 & + & $1 / 256$ & M \\
\hline 7 & + & $1 / 8$ & M \\
\hline 8 & + & $1 / 32$ & M \\
\hline 9 & + & $1 / 4$ & M \\
\hline 10 & - & $1 / 1$ & M \\
\hline 11 & Fracamente + & $1 / 2$ & M \\
\hline 12 & + & $1 / 256$ & M \\
\hline
\end{tabular}

Tabela1: Sorologia (ID [Imunodifusão] e CIE [Contraimunoeletroforese]) de indivíduos com a doença ativa. 


\section{2-Obtenção do antígeno de P. brasiliensis}

A obtenção da glicoproteina de $43 \mathrm{Kda}$ (gp43) do P. brasiliensis foi realizada no laboratório de Micologia da UNESP - Campus Araraquara, em colaboração com a Prof. Dra. Maria J. S. Mendes-Giannini.

O extrato de antígeno de P. brasiliensis (gp43), foi obtido de filtrado de cultura conforme descrito por Mendes-Giannini, 1989. As células leveduriformes foram cultivadas em meio Fava Netto a $35^{\circ} \mathrm{C}$ por 8 a 10 dias e depois cultivadas em meio Casal's modificado pela substituição de caseína por asparagina e adicionado $10 \mu$ de tiamina por $\mathrm{mL}$. Posteriormente foi adicionado timerosal na diluição final de 1: 10000 o meio foi centrifugado a 400g por 30 minutos. O sobrenadante foi dializado contra água destilada por $48 \mathrm{~h}$ à $4^{\circ} \mathrm{C}$ e então concentrado $10 \mathrm{X}$ por evaporação. Após centrifugação a $400 \mathrm{~g}$ por 10 minutos, o total de proteínas do filtrado foi determinado pelo método de LOWRY, 1951. A glicoproteína de $43 \mathrm{kDa},(\mathrm{GP} 43)$ foi purificada por cromatografia em gel (Sephadex G-50) e cromatografia de afinidade em coluna de proteína usando anti-soro de coelho anti GP43 (MENDES-GIANNINI, 1989, MENDES-GIANNINI, 1990). Após purificação, foi obtido também um filtrado de cultura sem gp43, denominado apenas filtrado.

Para a obtenção de gp43 metaperiodatada, uma alíquota de $3 \mathrm{ml}$ do antígeno gp43 foi oxidada com um volume igual de solução de metaperiodato de sódio a 100 mM por 18 horas a $4^{\circ} \mathrm{C}$ em câmara escura. A reação foi interrompida pela adição de quantidade equimolar de glicerol, e incubação por 15 minutos a $4^{\circ} \mathrm{C}$. Em seguida adicionou-se $100 \mathrm{mM}$ de borohidrato de sódio por 2 horas a $4^{\circ} \mathrm{C}$. Após esse tratamento o antígeno foi dialisado contra água destilada por 18 horas a $4^{\circ} \mathrm{C}$. (PUCCIA et al, 1991) 


\section{3 - Obtenção de células mononucleares de sangue periférico de pacientes, controles curados e indivíduos não expostos ao fungo para avaliação da resposta linfoproliferativa}

Para o ensaio de linfoproliferação foram utilizados os antígenos gp43, filtrado de cultura e gp43 tratada com metaperiodato, além de extrato antígêncio de Candida albicans (CMA - Candida Metabolic Antigen) obtido comercialmente (Bio-Rad, Califórnia, USA), como antígeno fúngico controle e o mitógeno de Pokeweed (PWM), como controle positivo de estimulação de linfócitos.

Suspensões de células mononucleares do sangue periférico $(\mathrm{CMN})$ foram obtidas através de gradiente de densidade FICOLL-HYPAQUE a partir de sangue periférico heparinizado, lavados por 2 vezes em RPMI 1640 e ajustadas para a concentração de 2x10 $/ \mathrm{mL}$. As células foram cultivadas em placas de 96 wells (Costar, USA), em volume de $0,1 \mathrm{ml} /$ well contendo $2 \times 10^{6}$ de CMN, em meio RPMI 1640 , enriquecido a $10 \%$ de pool de soro $\mathrm{AB}$ obtido comercialmente (Sigma) suplementado de gentamicina $(10 \mu \mathrm{g} / \mathrm{ml})$, juntamente com uma triplicata de cada antígeno em volume de 0,1 ml/well. Estas foram mantidas em estufa (Forma Scientific) a $37^{\circ} \mathrm{C}$, em atmosfera de $5 \%$ de $\mathrm{CO} 2$ por um período de 6 dias. Dezoito horas antes do término do cultivo, as células foram pulsadas com timidina tritiada (3H-Tdr) (Amersham International, UK), $1 \mathrm{uCi} /$ well, e aspiradas com o auxílio de coletor de células automático (Cell Harvester) em membrana de fibra de vidro (Wallac). A radioatividade incorporada foi medida em contador Betaplate 1205 (Wallac) e o resultado apresentado em média aritmética de triplicata dos "wells" estimulados, menos a medida aritméticas das triplicatas não estimuladas, por expressar de forma mais consistente e discriminativa os resultados (BENARD, et al. 1995 , BENARD, et al. 1996, CACERE et al, 


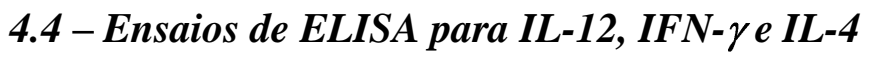

As placas de ELISA foram sensibilizadas com $4 \mu \mathrm{g} / \mathrm{mL}$ do anticorpo de captura para IL-12, IFN- $\gamma$ e IL-4 (Couting) (R\&D) e incubadas overnight a $4^{\circ} \mathrm{C}$. Em seguida as placas foram lavadas 3X com PBS 0,05\% de Tween 20 (solução de lavagem). As placas de IL-4- e IFN- $\gamma$ foram bloqueadas com PBS $1 \%$ de BSA e 5\% de Sucrose, e a placa para IL-12 foi bloqueada com PBS $1 \%$ de BSA. E todas as placas foram incubadas por 2 horas a temperatura ambiente.

Após a incubação as placas foram lavadas novamente e em seguida adicionada a curva (Standar, R\&D) diluída em PBS 1\% BSA para as citocinas IL-12 e IFN- $\gamma$. Para a IL-4 a diluição da curva foi realizada com tampão Tris $0,1 \%$ BSA + 0,05\% Tween 20. As curvas foram iniciadas em $2000 \mathrm{pg} / \mathrm{mL}, 1000 \mathrm{pg} / \mathrm{mL}$ e $2000 \mathrm{pg} / \mathrm{mL}$ respectivamente em diluição seriada. Em paralelo foram adicionados os sobrenadantes. As placas foram incubadas por 2 horas a temperatura ambiente, e ao término dessa incubação as mesmas foram lavadas. Após incubação foi adicionado o anticorpo de detecção (Biotinilado, R\&D) nas concentrações de $175 \mathrm{ng} / \mathrm{mL}$ para IL-12, $100 \mathrm{ng} / \mathrm{mL}$ para IFN- $\gamma$ e 12,5 ng/mL para IL-4 em solução diluente, e novamente incubadas a temperatura ambiente por 2 horas. Em seguida as placas foram lavadas, e então adicionada a Streptavidina-HRP (R\&D) em uma diluição de 1/200 sendo novamente incubadas por 20 minutos a temperatura ambiente. Foi adicionado Peróxido de Uréia e TMB (Substrato) na proporção 1/1 e incubadas novamente por 20 minutos a temperatura ambiente e sob proteção da luz. Por fim foi adicionado $\mathrm{H}_{2} \mathrm{SO}_{4} 2 \mathrm{M}$ (Solução de Parada) e imediatamente analisada na leitora de ELISA a 450nm. 


\section{5-Ensaio de ELISA para detecção de IL-10}

A placa de ELISA foi sensibilizada com $2,5 \mu \mathrm{g} / \mathrm{mL}$ do anticorpo de captura (ENDOGEN, USA) e incubada overnight a $4^{\circ} \mathrm{C}$. Em seguida a placa foi lavada $3 \mathrm{X}$ com PBS 0,05\% de Tween 20 (Solução de Lavagem) e bloqueada com PBS 1\% de BSA + 5\% de Sucrose por 2 horas a temperatura ambiente. A placa então foi lavada novamente e foi adicionado a curva padrão no intervalo de 1000 à 10 pg/mL (ENDOGEN) em diluição seriada em PBS 1\% BSA (Solução Diluente). Concomitantemente, foi adicionado os sobrenadantes e o anticorpo de detenção Biotinilado na concentração de $1 \mu \mathrm{g} / \mathrm{mL}$ (ENDOGEN) e a placa incubada a temperatura ambiente por 2 horas. Após a incubação a placa foi lavada novamente e adicionado Streptavidina marcada com peroxidase (ENDOGEN) em uma diluição 1/5000 e incubada por 20 minutos a temperatura ambiente. Em seguida, a placa foi lavada e foi adicionado o substrato tetrametilbenzidina (Organon) e a placa incubada a temperatura ambiente por 20 minutos sob proteção da luz. Após a incubação foi adicionado ácido sulfúrico $\left(\mathrm{H}_{2} \mathrm{SO}_{4}\right)$ 2M (Solução de Parada) e imediatamente analisada na leitora de ELISA no filtro de $450 \mathrm{~nm}$.

\section{6- Análise estatística}

As comparações entre os resultados dos 3 grupos de indivíduos foram realizadas utilizando-se ANOVA com pós-teste de Dunnet. 


\section{5-RESULTADOS}

A escolha da gp43 de $P$. brasiliensis se deve aos estudos anteriores do nosso laboratório e de outros grupos que descrevem sua importância como fração imunodominante Utilizamos ainda um filtrado de cultura livre de gp43, e a gp43 tratada com metaperiodato para retirada de sua fração glicídica a fim de comparar sua capacidade de ativação celular.

\section{(Figura 2)}

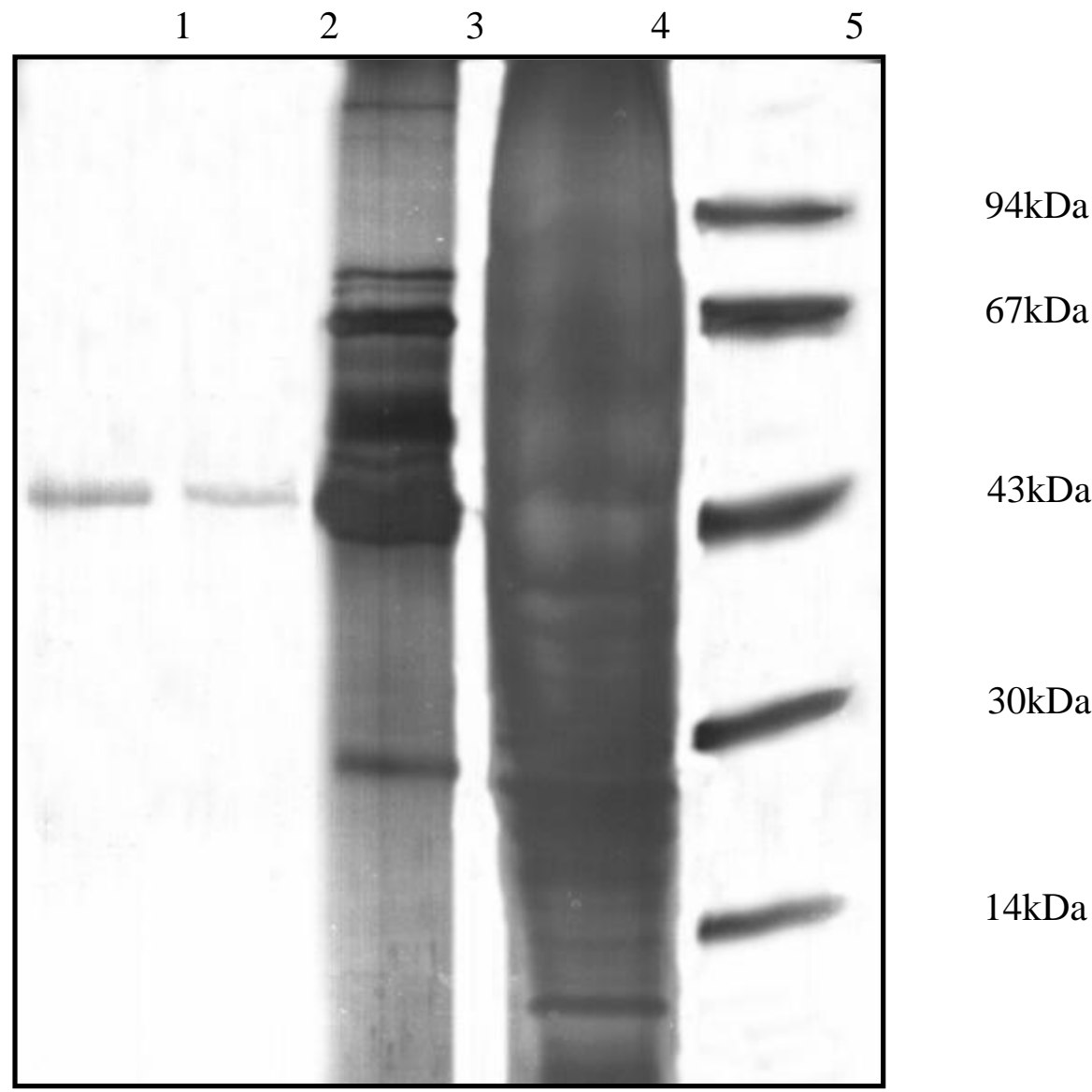

Figura 2- Gel demonstrando as bandas de: 1 - Glicoproteína de 43KDa de $P$. brasiliensis 2 - Glicoproteína de 43KDa de P. brasiliensis tratada com metaperiodato de sódio 3 - Antígeno filtrado de cultura de P. brasiliensis (isolado 18) 4 - Antígeno filtrado de cultura de $P$. brasiliensis (isolado 18) com ausência da glicoproteína de 43Kda 5 - Marcador de peso molecular 
Para avaliarmos a melhor concentração para o filtrado de cultura sem a gp43 e da gp43 tratada com metaperiodato, realizamos alguns ensaios de linfoproliferação com células mononucleares de 3 indivíduos curados de PCM. Os resultados sugerem uma resposta linfoproliferativa discreta para o filtrado de cultura na concentração de $50 \mu \mathrm{g} / \mathrm{mL}$ quando comparada com as outras diluições e o basal (células não estimuladas) Gráfico 1.

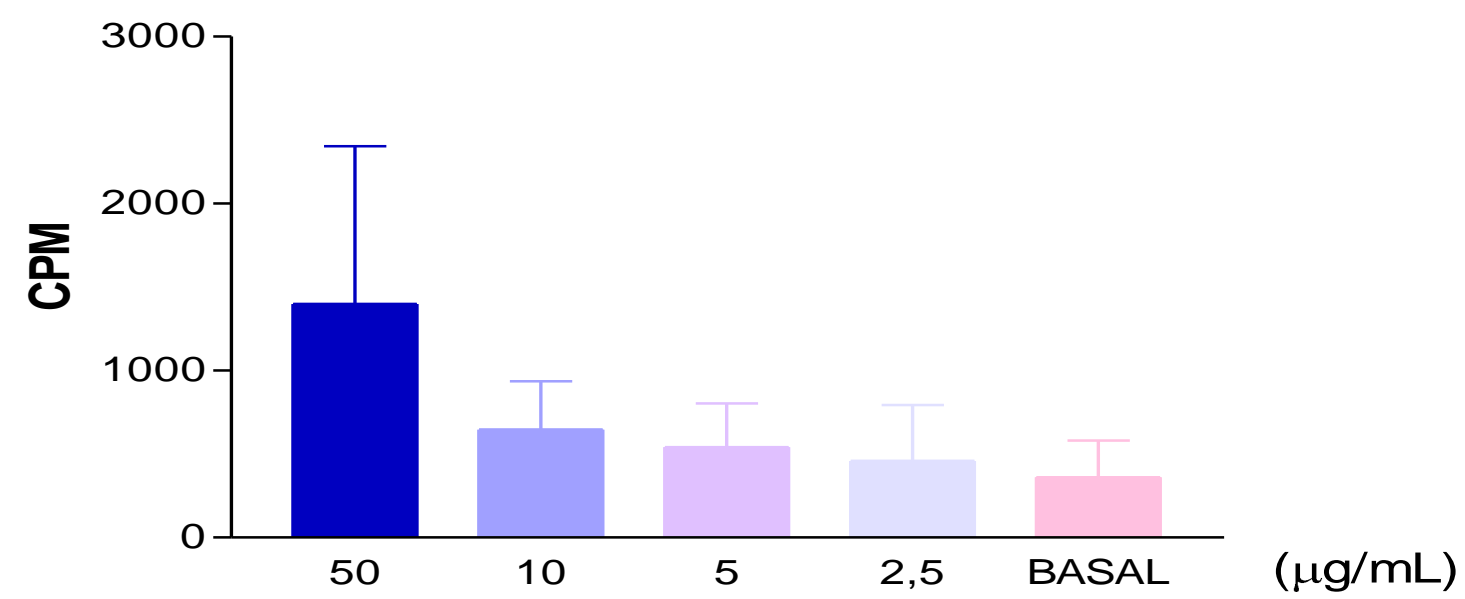

Gráfico 1: Avaliação da resposta linfoproliferativa em 3 indivíduos curados de PCM para avaliação da concentração de uso do filtrado de cultura.

Já para a gp43 tratada com metaperiodato, não obtivemos uma boa resposta proliferetiva com nenhuma das diluições, mas a escolha da concentração de $5 \mu \mathrm{g} / \mathrm{mL}$ se deu devido à discreta proliferação quando comparada com as outras diluições e com o basal (células não estimuladas), como observado no Gráfico 2. 


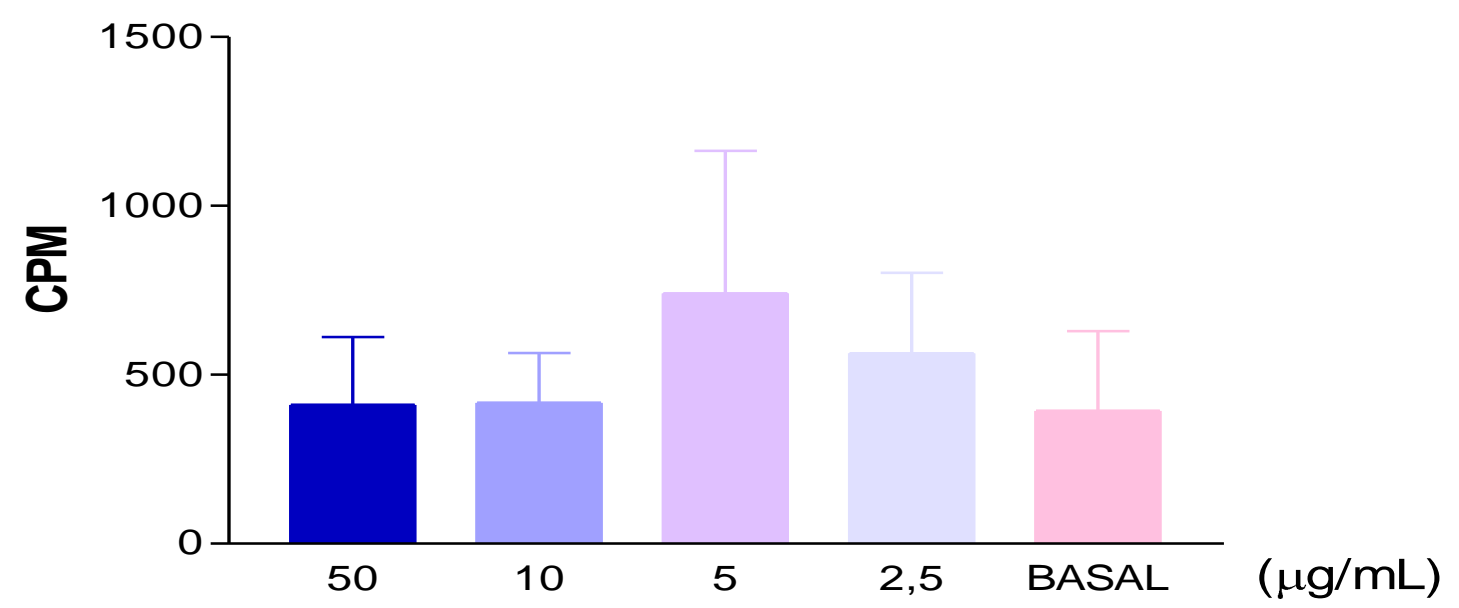

Gráfico 2: Avaliação da resposta linfoproliferativa em 3 indivíduos curados de PCM para avaliação da concentração de uso da gp43 metaperiodatada.

Desta forma para a avaliação da resposta imune in vitro utilizamos as seguintes concentrações finais: gp43 - $20 \mu \mathrm{g} / \mathrm{mL}$, filtrado de cultura- $50 \mu \mathrm{g} / \mathrm{mL}$, para gp43 metaperiodatada $-5 \mu \mathrm{g} / \mathrm{mL}$.

Células mononucleares dos 13 indivíduos saudáveis não expostos ao P. brasiliensis não apresentaram resposta linfoproliferativa com gp43 e gp43 metaperiodatada (média de $351,5 \pm 82,8 \mathrm{cpm}$ para gp43 e de 809,3 \pm 307,5 cpm para metaperiodatado), tendo uma discreta, porém significativa resposta com o filtrado quando comparada com o basal (1316 \pm $350,5 \mathrm{cpm}$ para filtrado e de 445,7 $\pm 83,5$ com para o basal). Quando comparada a resposta entre os antígenos neste grupo, observamos uma resposta significantivamente maior do filtrado com relação a gp43. No entanto, estes indivíduos apresentaram valores esperados de resposta proliferativa para o antígeno metabólico de Cândida albicans (média de $19150 \pm$ $5585 \mathrm{cpm}$ ) e para o mitógeno PWM (média de $35800 \pm 4590 \mathrm{cpm}$ ), considerando a 
referência de valores utilizada em nosso laboratório (para PWM média de $31060 \pm 1021$ e para CMA média de $10580 \pm 833 \mathrm{cpm}$ ) Como observado no Gráfico 3.

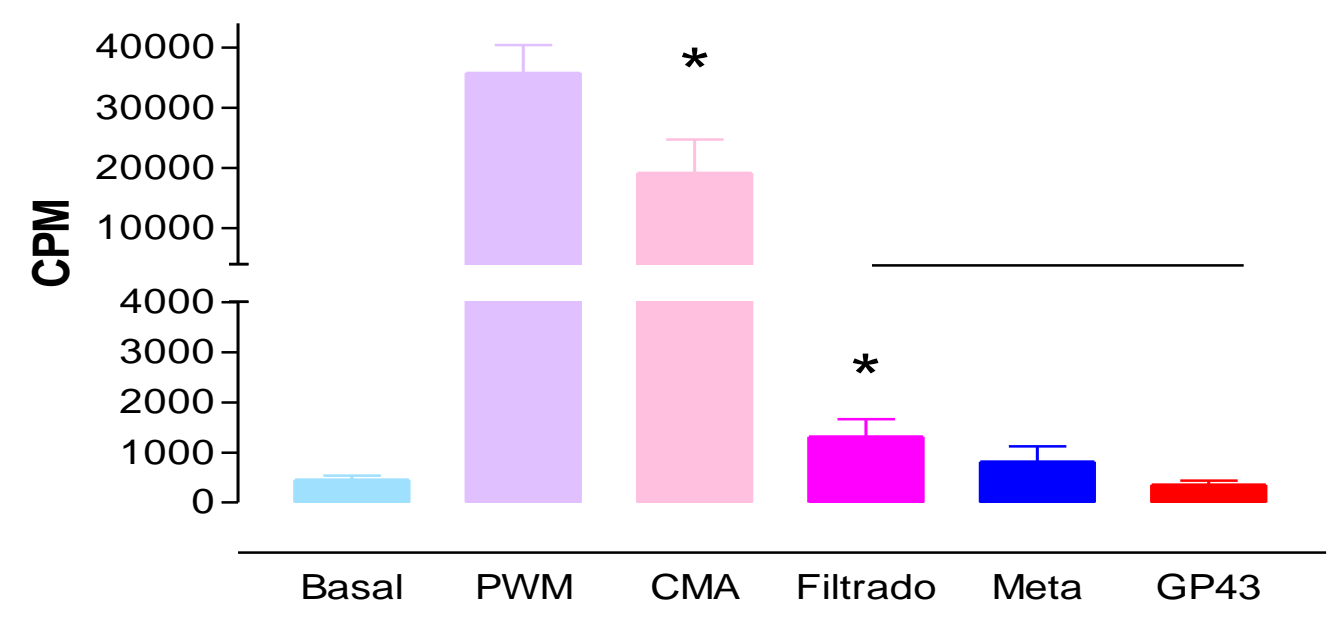

Gráfico 3: Linfoproliferação do grupo controle de indivíudos sadios (n=13) com os diferentes antígenos do P. brasiliensis - filtrado de cultura sem gp43 (FILT), gp43 tratada com metaperiodato (MET) e gp43 (gp43) e antígenos de pokeweed (PWM) como controle positivo e antígeno de Candica albicans (CMA) como controle de antígeno fúngico não relacionado ao P. brasiliensis. A barra acima dos grupos significa que houve diferença significativa entre eles $(P>0.10)$ e o* significa que houve diferença significante com relação ao basal (células não estimuladas).

O mesmo ensaio descrito acima foi realizado com células mononucleares de 23 indivíduos curados de PCM, uma vez que, dados anteriores demonstram recuperação da resposta proliferativa antígeno-específica após tratamento e cura clínica (BENARD et al,1997). Observamos resposta considerável aos antígenos derivados do fungo (média de $2561 \mathrm{com} \pm 657 \mathrm{cpm}$ para filtrado, $1599 \pm 497 \mathrm{cpm}$ para metaperiodatado e $4887 \pm 1422$ cpm para gp43), com resposta significativamente maior com a gp 43 quando comparada 
com a gp43 metaperiodatada. Este resultado demonstra o reconhecimento dos antígenos, principalmente da gp43, pelos linfócitos $\mathrm{T}$ de memória, e também reposta proliferativa preservada para o antígeno metabólico de Cândida albicans (média de $6788 \pm 1717$ cpm) e para o mitógeno PWM (média de 24320 × 2199 cpm), como observado no Gráfico 4.

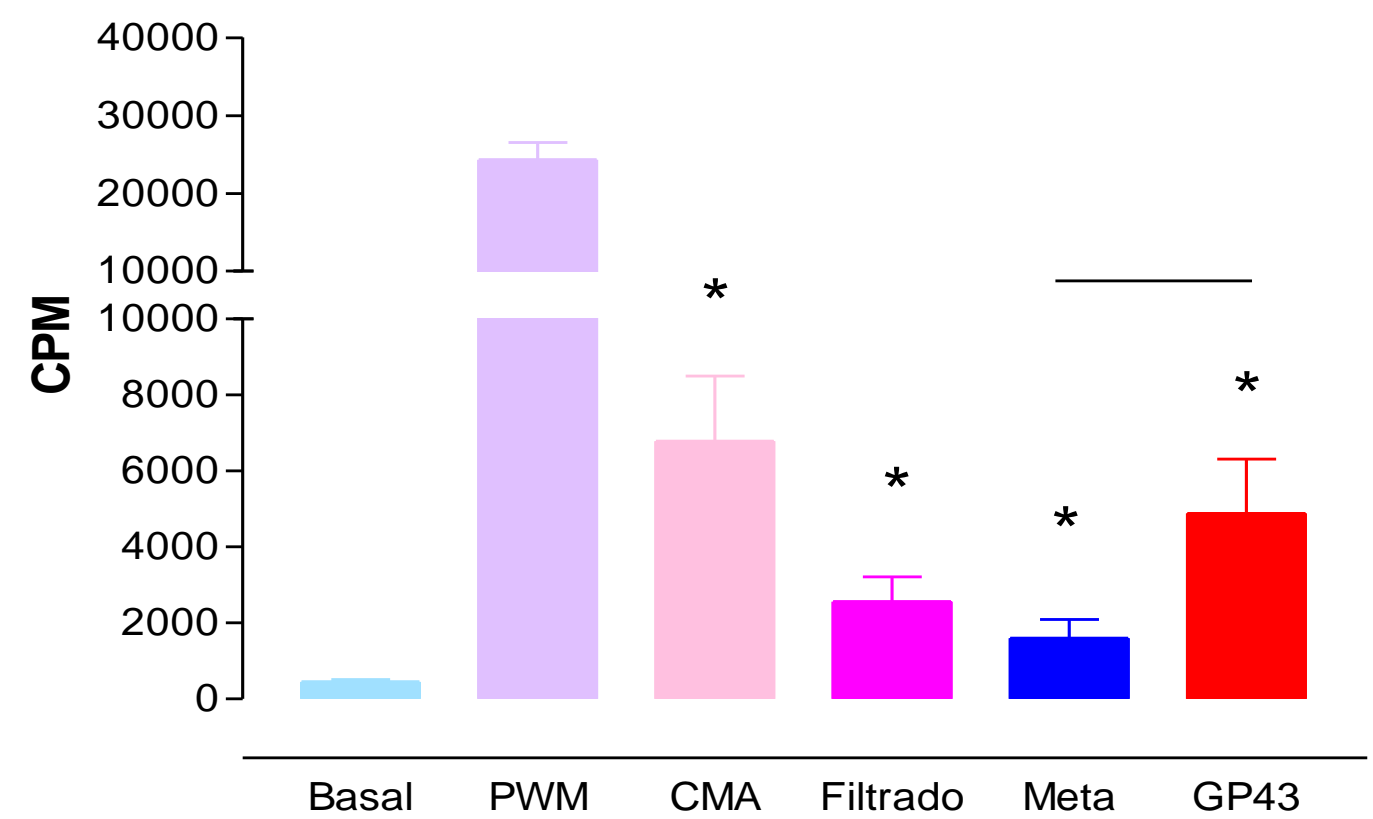

Gráfico 4: Linfoproliferação do grupo controle de indivíduos curados (n=23) de PCM com os diferentes antígenos derivados do P. brasiliensis. A barra acima dos grupos significa que houve diferença significativa entre eles $(P>0.10)$ e o * significa que houve diferença significante com relação ao basal (células não estimuladas).

Também foram realizados esses experimento com células mononucleares de 12 indivíduos com a doença ativa, todos com a forma crônica.. Corroborando dados da literatura, foi observada baixa resposta para os antígenos derivados do fungo (média de 1271 
cpm \pm 689 para filtrado, $1354 \pm 918 \mathrm{cpm}$ para metaperiodatado e $1916 \pm 983 \mathrm{cpm}$ para gp43) e valores de linfoproliferação normais para o antígeno metabólico de Cândida albicans (média de $8633 \pm 1534$ cpm) e para o mitógeno PWM (média de $34890 \pm 3718$ cpm), como observado no Gráfico 5.

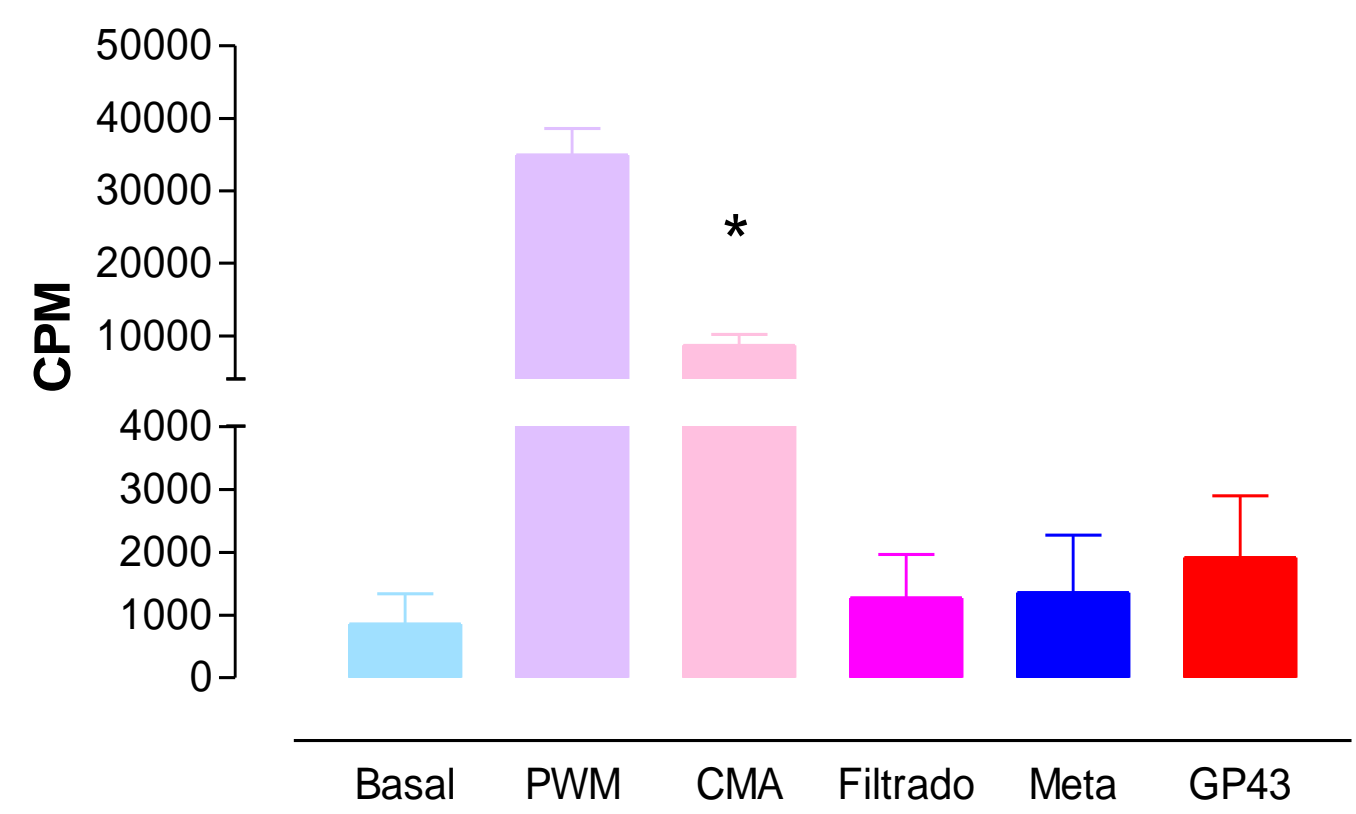

Gráfico 5: Linfoproliferação do grupo de individuos com a doença ativa (forma crônica da PCM) (n=12) com os diferentes antígenos derivados do P. brasiliensis. $O *$ significa que houve diferença significante com relação ao basal (células não estimuladas).

Em relação à produção de citocinas, foram avaliados as citocinas IFN- $\gamma$, IL-10, IL-4 e IL-12 em sobrenadantes de cultura de células mantidas apenas com o meio ou estimuladas com os diferentes antígenos do $P$. brasiliensis, e CMA como controle. A coleta de sobrenadante para análise de IL-10 e IL-12 foi realizada após 18 horas de cultura e para 
avaliação de IL-4 e IFN- $\gamma$ a coleta foi realizada após 72 horas conforme estudos prévios em nosso laboratório. (ROMANO et al, 2002; BENARD et al, 2001)

Analisamos a produção dessas citocinas em 10 pacientes com a doença ativa, 11 controles curados e 10 indivíduos saudáveis não expostos ao fungo através de ELISA.

Com relação à produção de IL-12, observamos maior produção desta citocina com o estímulo de gp43 nos controles curados $(136,2 \pm 13,5 \mu \mathrm{g} / \mathrm{mL})$ que com filtrado $(36,4 \pm 9,2$ $\mu \mathrm{g} / \mathrm{mL})$ e gp43 metaperiodatada $(27,9 \pm 6,5 \mu \mathrm{g} / \mathrm{mL})$. A produção basal foi discreta $(19,9 \pm$ $3,9 \mu \mathrm{g} / \mathrm{mL})$ e aumentada na presença de CMA $(58,8 \pm 9,8 \mu \mathrm{g} / \mathrm{mL})$.

Já para os pacientes não obtivemos produção desta citocina com gp43 (23,4 \pm 8,6 $\mu \mathrm{g} / \mathrm{mL}$ vs. $21,2 \pm 6,8 \mu \mathrm{g} / \mathrm{mL}$ de produção basal), porém uma produção significante na presença de filtrado de cultura $(63,2 \pm 5,0 \mu \mathrm{g} / \mathrm{mL})$, mas assim como nos controles, baixa produção com gp43 metaperiodatada $(29,9 \pm 6,1 \mu \mathrm{g} / \mathrm{mL})$. A produção com CMA foi de 62,3 $\pm 14,1 \mu \mathrm{g} / \mathrm{mL}$, similar à dos controles curados.

Em relação aos indivíduos sadios, a produção foi baixa tanto para gp43 (31,7 \pm 2,0 $\mu \mathrm{g} / \mathrm{mL})$, quanto para filtrado $(30,8 \pm 1,7 \mu \mathrm{g} / \mathrm{mL})$ e gp43 metaperiodatada $(30,2 \pm 1,9$ $\mu \mathrm{g} / \mathrm{mL})$. A produção basal foi de $30,4 \pm 2,0 \mu \mathrm{g} / \mathrm{mL}$ e com CMA foi de $31,2 \pm 2,0 \mu \mathrm{g} / \mathrm{mL}$. Como podemos observar no Gráfico 6. 


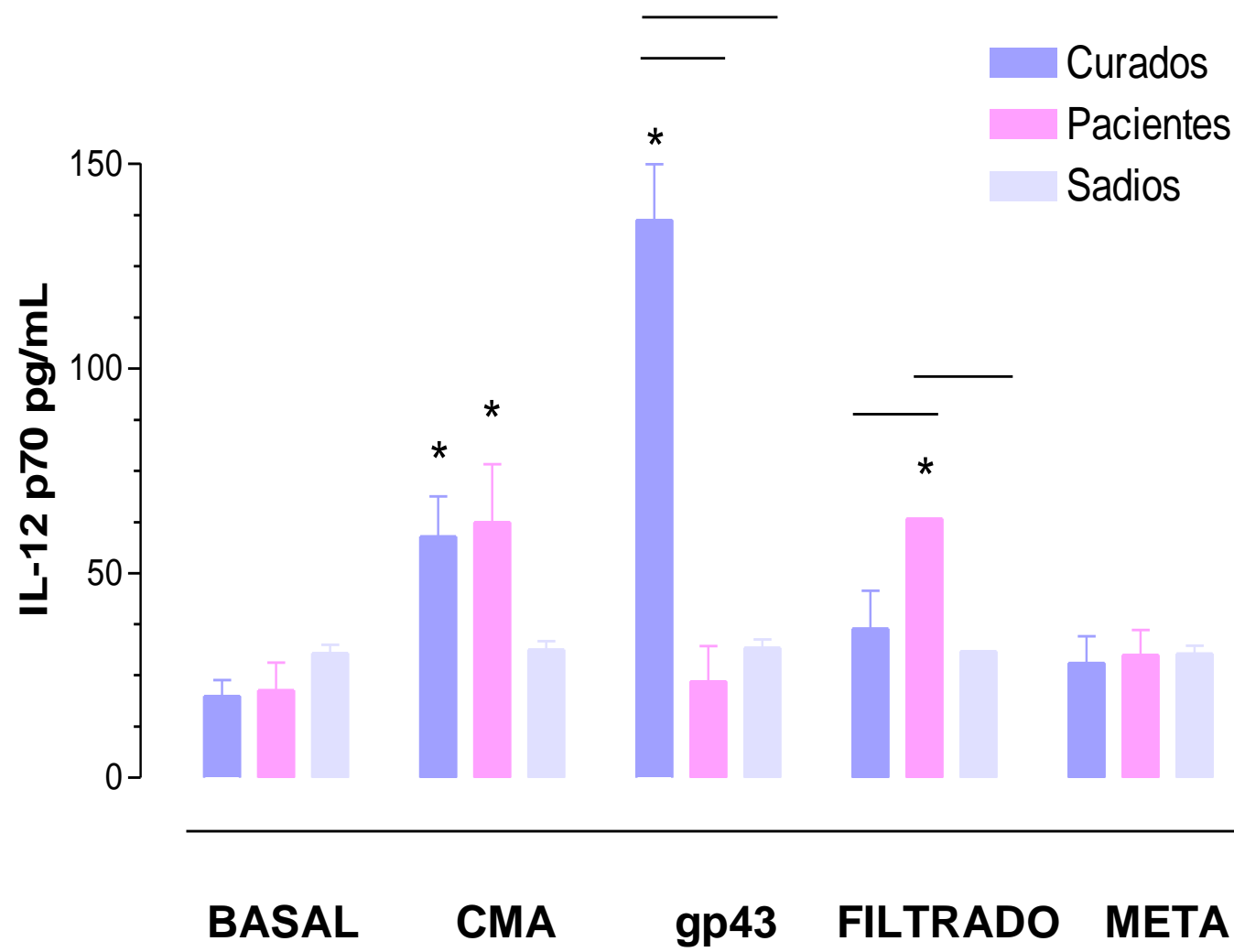

Gráfico 6: Detecção de IL-12 em sobrenadantes de cultura de células coletadas após 18hs de estímulo com antígeno de Cândida albicans (CMA), gp43 de P. brasiliensis, filtrado de cultura sem gp43 (filtrado) e gp43 tratada com metaperiodato (meta). A barra acima dos grupos significa que houve diferença significativa entre eles $(P>0.10)$ e o * significa que houve diferença significante com relação ao basal (células não estimuladas)

Com relação à IFN- $\gamma$, observamos uma produção significante desta citocina por células de controles curados quando estimuladas com gp43 $(92,3 \pm 11,9 \mu \mathrm{g} / \mathrm{mL})$, mas não com filtrado $(48,6 \pm 14,7 \mu \mathrm{g} / \mathrm{mL})$ ou com gp43 metaperiodatada $(55,2 \pm 10,9 \mu \mathrm{g} / \mathrm{mL})$, quando comparada à produção basal $(39,6 \pm 8,7 \mu \mathrm{g} / \mathrm{mL})$. A produção com CMA $(79,9 \pm 15,0$ $\mu \mathrm{g} / \mathrm{mL})$ foi significantivamente maior que o basal $(39,6 \pm 8,7 \mu \mathrm{g} / \mathrm{mL})$. 
Já os pacientes apresentaram uma baixa produção desta citocina com todos os antígenos do fungo: gp43 $(45,6 \pm 10,6 \mu \mathrm{g} / \mathrm{mL})$, filtrado $(53,5 \pm 15,4 \mu \mathrm{g} / \mathrm{mL})$ e gp43 metaperiodatada $(60,7 \pm 10,5 \mu \mathrm{g} / \mathrm{mL})$. Observando uma significativa produção apenas com CMA $(87,8 \pm 14,0 \mu \mathrm{g} / \mathrm{mL})$ quando comparada com o basal $(43,5 \pm 8,5 \mu \mathrm{g} / \mathrm{mL})$.

Assim como os pacientes, os indivíduos sadios apresentaram baixa produção para os antígenos gp43 $(41,7 \pm 11,4 \mu \mathrm{g} / \mathrm{mL})$, filtrado $(53,6 \pm 11,3 \mu \mathrm{g} / \mathrm{mL})$ e gp43 metaperiodatada $(47,5 \pm 10,5 \mu \mathrm{g} / \mathrm{mL})$, não sendo significativamente diferentes quando comparados com a produção basal $(37,1 \pm 7,6 \mu \mathrm{g} / \mathrm{mL})$. Houve, entretanto, produção importante com CMA (76,6 $\pm 21,2 \mu \mathrm{g} / \mathrm{mL})$. (Gráfico 7).

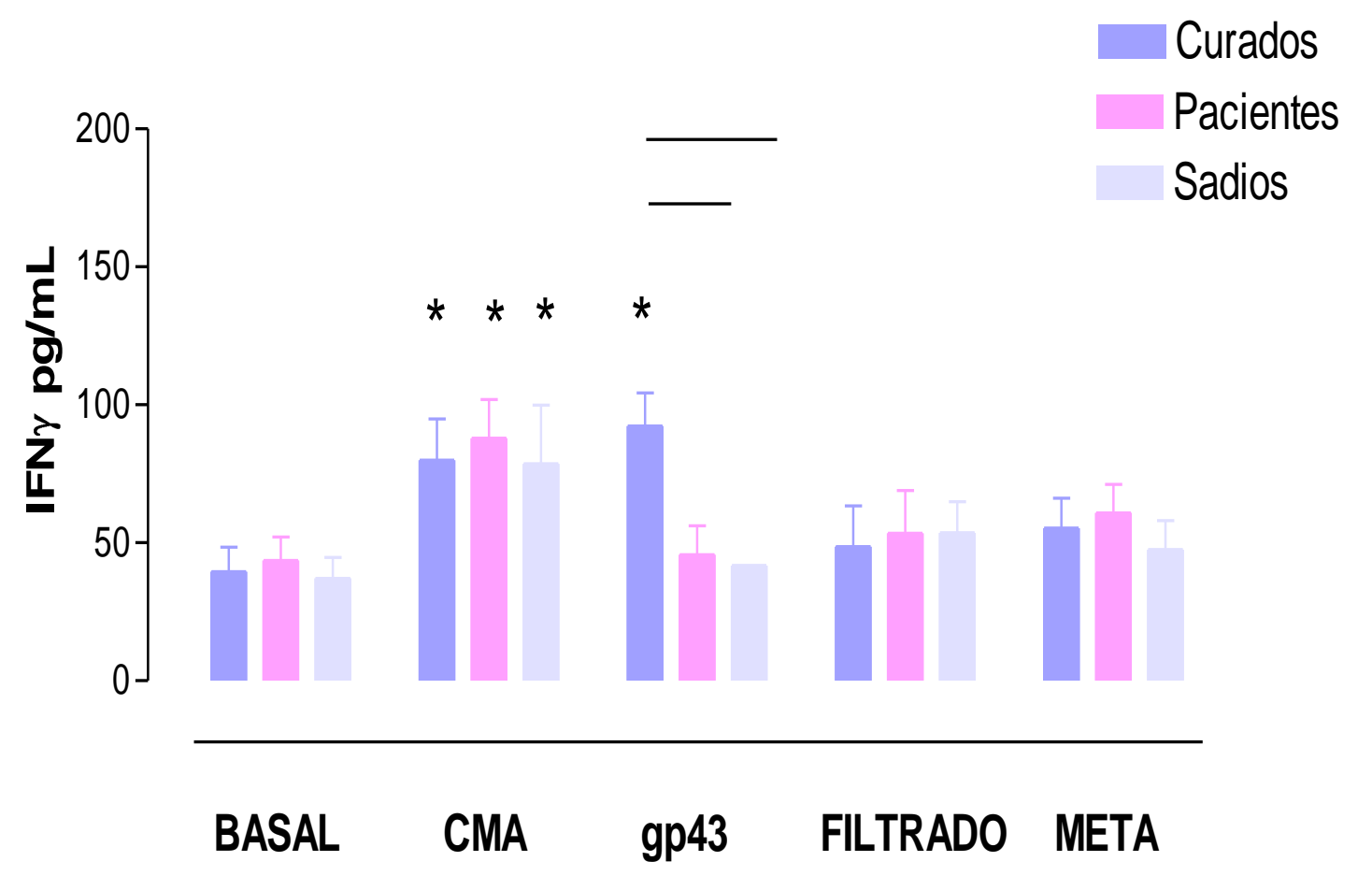

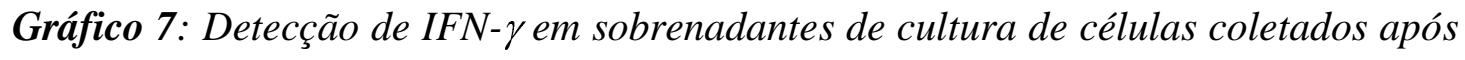
72 hs de estímulo com antígeno metabólico de Cândida albicans (CMA), gp43 de P. brasiliensis, filtrado de cultura sem gp43 (filtrado) e gp43 tratada com metaperiodato 
(meta). A barra acima dos grupos indica diferença significativa entre eles $(P>0.10) e^{*}$ indica diferença significativa em relação ao basal (células não estimuladas).

Em relação a IL-10, observamos uma maior produção desta citocina por células de pacientes com gp43 $(283,5 \pm 81,7 \mu \mathrm{g} / \mathrm{mL})$ e com filtrado $(285,5 \pm 77,2 \mu \mathrm{g} / \mathrm{mL})$; já para gp43 metaperiodatada não houve produção significante $(150,1 \pm 22,5 \mu \mathrm{g} / \mathrm{mL})$, quando comparada ao basal $(82,5 \pm 22,4 \mu \mathrm{g} / \mathrm{mL})$. Na presença de CMA também houve produção apenas discreta, não significativa em relação ao basal $(132,9 \pm 24,7 \mu \mathrm{g} / \mathrm{mL})$.

Já os controles curados obtiveram uma baixa produção com gp43 $(86,1 \pm 10,1 \mu \mathrm{g} / \mathrm{mL})$, mas uma produção significativa com filtrado $(328,6 \pm 80,9 \mu \mathrm{g} / \mathrm{mL})$ e, assim como nos pacientes, pouca produção com gp43 metaperiodatada $(104,9 \pm 22,2 \mu \mathrm{g} / \mathrm{mL})$. A produção basal foi de $99,1 \pm 20,4 \mu \mathrm{g} / \mathrm{mL}$ e de $108,9 \pm 19,5 \mu \mathrm{g} / \mathrm{mL}$ para CMA.

Os indivíduos sadios apresentaram, assim como para as outras citocinas, baixa produção de IL-10 para todos os três antígenos de $P$. brasileinsis: gp43 $(125,1 \pm 11,3$ $\mu \mathrm{g} / \mathrm{mL})$, filtrado $(129,2 \pm 14,5 \mu \mathrm{g} / \mathrm{mL})$ e gp43 mataperiodatada $(94,6 \pm 11,6 \mu \mathrm{g} / \mathrm{mL})$, não havendo diferença significativa quando comparados com o basal $(90,6 \pm 10,5 \mu \mathrm{g} / \mathrm{mL})$. Também não houve produção aumentada desta citocina com CMA $(93,1 \pm 8,8 \mu \mathrm{g} / \mathrm{mL})$. (Gráfico 8). 


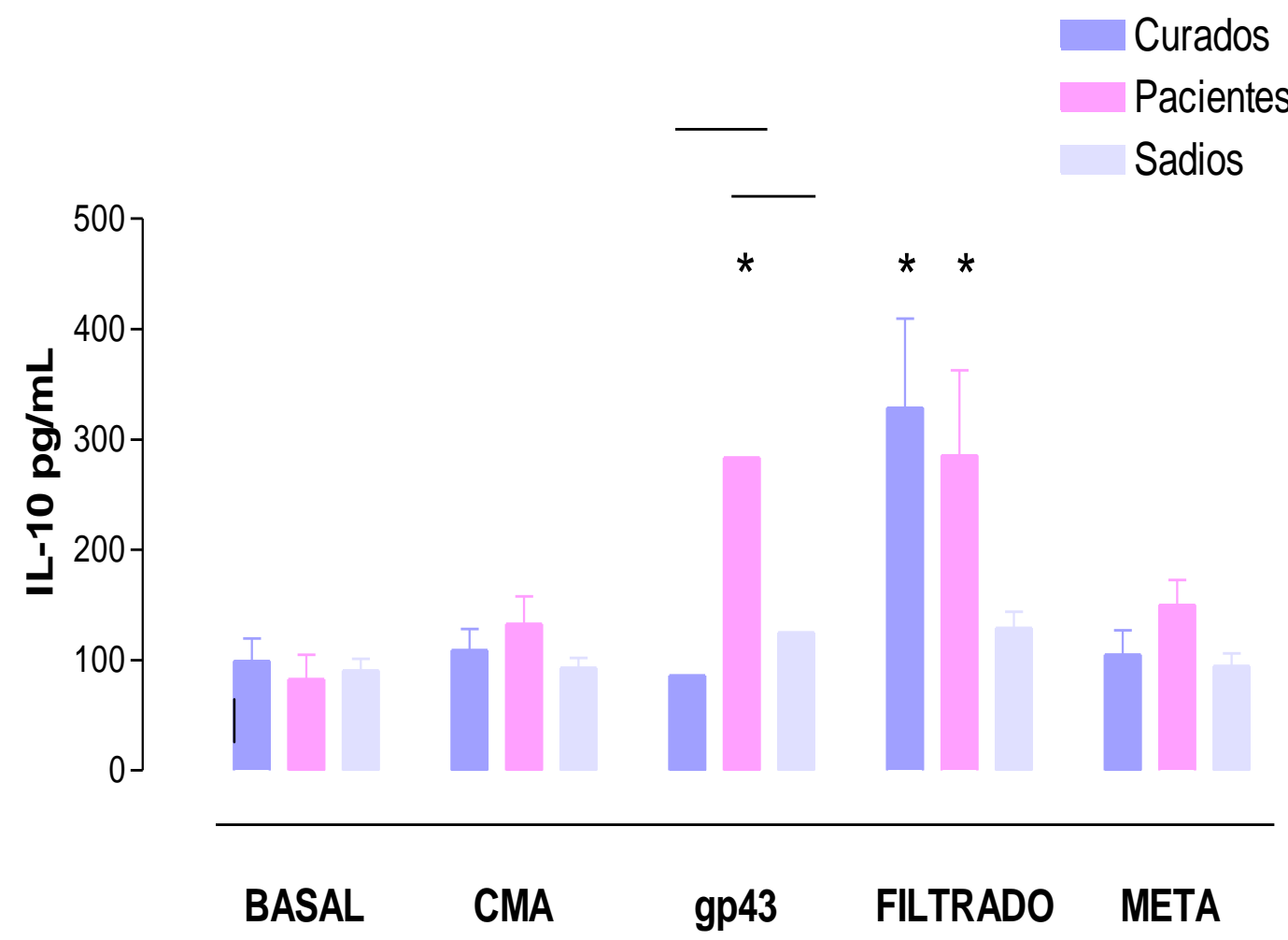

Gráfico 8: Detecção de IL-10 em sobrenadantes de cultura de células coletados após 18hs de estímulo com antígeno metabólico de Cândida albicans (CMA), gp43 de P. brasiliensis, filtrado de cultura sem gp43 (filtrado) e gp43 metaperiodatada (meta). A barra acima dos grupos indica diferença significativa entre eles $(P>0.10) e *$ sindica diferença significativa em relação ao basal (células não estimuladas).

Não foi detectada IL-4 acima do "cut-off" do teste em nenhuma das condições estudadas. 


\section{6- DISCUSSÃO}

A paracoccidioidomicose é uma doença que ocorre endemicamente em várias regiões da América Latina. O Brasil é um dos países com maior freqüência de casos sendo de grande importância estudos que permitam melhores abordagens terapêuticas desta micose, visto que afeta principalmente indivíduos na sua fase mais produtiva, e apesar de baixa mortalidade, está associada a grande morbidade e tratamentos prolongados.

Considerada o principal mecanismo de defesa contra a PCM, a imunidade celular é muito estudada, tanto em modelos experimentais quanto em humanos. Um dos achados mais importantes para o estudo da interação hospedeiro-parasita nesta micose foi a descrição e caracterização da gp43, uma glicoproteina de $43 \mathrm{KDa}$ secretada pelo fungo em sua fase leveduriforme, e que é considerada o componente antigênico imunodominante de $P$. brasiliensis. (TABORDA et al. 1994; ALBUQUERQUE et al. 2005). Neste estudo procuramos então confirmar sua importância primordial na resposta imune, analisando a sua capacidade de estimulação dos linfócitos comparativamente à de por filtrado de cultura de $P$. brasiliensis, rico em componentes derivados do fungo, porém livre de gp43, e verificar a importância de seu componente polissacarídico na resposta imune celular, utilizando gp43 tratada com metaperiodato que se mostrou previamente imunoreativa em estudos sorológicos realizados por outros grupos como ELISA e Dot Immunobinding.

Para avaliarmos a resposta imune celular, escolhemos os ensaios de linfoproliferação e ELISA para detecção de diferentes citocinas relevantes na regulação da resposta imune antiP. brasiliensis (IL-4, IL-10, IFN- $\gamma$ e IL-12). Foram utilizados, além dos antígenos derivados de $P$. brasiliensis, o mitógeno PWM como controle positivo e uma suspensão antigênica de Candida Albicans como antígeno fúngico controle, não relacionado a $P$. brasiliensis. Estes 
ensaios foram previamente utilizados em nosso laboratório (ROMANO et al. 2002; BENARD et al. 1996) e em outros laboratórios (como por exemplo, MUSSATTI et al.1976; MOTA et al. 1985 KUROKAWA et al. 1998), e permitiram caracterizar melhor a desregulação da resposta imune celular na paracoccidioidomicose. A escolha destas citocinas especificamente se deve também a estudos anteriores de nosso grupo (BENARD et al. 2001; ROMANO et al. 2005; ROMANO et al. 2002) e de outros grupos (PERAÇOLI, et al. 2003; KUROKAWA et al. 2007; KARHAWI et al. 2000), mostrando a importância das mesmas na avaliação e regulação da resposta imune celular.

$\mathrm{Na}$ reposta proliferativa, como esperado, a gp43 mostrou-se ser realmente um antígeno importante de $P$. brasiliensis. Os resultados mostraram uma boa resposta linfoproliferativa para os controles curados e baixa proliferação para os indivíduos com a doença ativa, corroborando indicações prévias de que a gp43 está envolvida na anergia dos linfócitos T nesses indivíduos (CACERE et al.2002; ROMANO, et al. 2002; ROMANO et al. 2005; BENARD et al. 1996; BENARD et al. 1997). Além disso, para este ensaio, mostrou-se ser um antígeno específico do P. brasiliensis, pois se observou ausência de resposta proliferativa em $\mathrm{PBMC}$ de indivíduos sadios não expostos ao fungo frente a este antígeno.

Já para o filtrado de cultura livre de gp43, observamos que PBMC de indivíduos curados da PCM apresentaram resposta significativa, mas com magnitude menor em relação à gp43. Em indivíduos com a doença ativa observamos uma discreta resposta, não significativa em relação ao basal. Essa baixa resposta proliferativa indica que a hiporreatividade dos linfócitos T não é restrita apenas à gp43. Há componentes presentes no filtrado de cultura que induzem resposta proliferativa, ainda que discreta, de indivíduos curados, imunologicamente restabelecidos, porém não em indivíduos com a doença ativa. Neste sentido é importante ressaltar que a resposta a $C$. albicans foi comparável nos 2 
grupos, denotando que mesmo os pacientes com doença ativa preservam seu potencial de resposta imunológica a antígenos fúngicos não relacionados a $P$. brasiliensis. Finalmente, para os indivíduos sadios não expostos ao fungo, observamos uma discreta, porém significativa resposta proliferativa quando comparada com o basal, sugerindo que componentes existentes no filtrado induzem uma resposta inespecífica, representando um inconveniente para a utilização neste ensaio.

Com relação à gp43 tratada com metaperiodato, observamos uma baixa resposta proliferativa pelos PBMC de indivíduos curados quando comparados com os estímulos de gp43 e filtrado de cultura. Assim como o filtrado de cultura não houve reconhecimento antigênico pelos grupos de indivíduos com a doença ativa. Uma das hipóteses para essa baixa proliferação nos indivíduos curados de PCM seria a perda da capacidade de ligação aos receptores macrofágicos pela gp43 tratada (por exemplo: Toll like receptor 2, Toll like receptor 4 e receptores de manose): com o tratamento e a oxidação da fração polissacarídica da gp43, essa ligação seria possivelmente prejudicada, resultando em menor incorporação da gp43 pelas células apresentadoras de antígeno.

Em relação à detecção de citocinas, utilizamos sobrenadante de cultura coletados após18 hs para as citocinas IL-10 e IL-12 e 72 hs para as citocinas IFN- $\gamma$ e IL-4. Não foi possível, entretanto, detectar valores significantes (acima do cut-off da reação) para esta última citocina, reforçando dados da literatura de que esta metodologia não é a mais adequada para detecção da mesma, possivelmente pelo fato de que esta citocina é rapidamente consumida do sobrenadante de cultura (ALHEIM et al, 2001).

Com o estímulo de gp43 observamos uma baixa produção de IL-12 e IFN- $\gamma$ e alta produção de IL-10 por PBMC de indivíduos com a doença ativa, em consonância com dados da literatura mostrando altos níveis de secreção de IL-10 (ROMANO et al. 2002; ROMANO 
et al. 2005) provavelmente pela sua atuação como inibidor de ativação dos macrófagos, regulando negativamente a resposta imune celular Th1, e, principalmente nos pacientes com a forma aguda/subaguda da doença, podendo favorecer uma resposta tipo Th2. Ao contrário dos pacientes com a doença ativa, os indivíduos curados de PCM produziram altos níveis de IL-12 e IFN- $\gamma$, e baixos níveis de IL-10 em resposta a gp43, indicando uma resposta Th1 e mostrando novamente o papel do balanço destas citocinas no controle da doença.

Já com o estímulo de filtrado de cultura observamos uma produção significativa de IL12 e IL-10, porém mais intensa da IL-10 ( 300 pg/mL vs. $~ 50$ pg/mL), e baixa produção de IFN- $\gamma$, por PBMC de indivíduos com a doença ativa. Aqui também os altos níveis de IL-10 poderiam explicar a inibição da resposta tipo Th1 e a ausência de produção de IFN- $\gamma$. Esse perfil de resposta pode ser explicado pelo fato do filtrado de cultura conter uma grande variedade de componentes secretados pelo fungo, sendo que estes componentes estimulariam monócitos já possivelmente pré-ativados in vivo pela exposição a antígenos circulantes, levando a uma maior reatividade dos mesmos e à secreção de IL-10 e IL-12 (PERAÇOLI et al, 2003). Indivíduos curados de PCM produziram baixos níveis de IL-12 e também de IFN- $\gamma$, porém altos níveis de IL-10. Nossa hipótese é que componentes do fungo presentes no filtrado de cultura ativem monócitos preferencialmente para a produção de IL10, levando á diminuição da secreção de IFN- $\gamma$ pelas células $\mathrm{T}$, da mesma forma que nos pacientes com a doença ativa. Portanto, consideramos que além da gp43, outros componentes secretados pelo fungo para o meio de cultura possam apresentar atividade imunoregulatória. Entretanto, uma estratégia para melhor avaliar a atividade destes componentes seria o isolamento e purificação dos componentes do filtrado, e posterior utilização em maiores concentrações nos ensaios biológicos, da mesma forma do que foi realizado com a gp43. Neste sentido, COLTRI et al. (2006) isolaram recentemente um componente do fungo, denominado paracoccina com propriedades imunoregulatória, e 
DINIZ et al. (2001), identificaram outras frações antigênicas de $P$. brasiliensis que induziam a secreção de citocinas, favorecendo a formação de granulomas.

Com o estímulo da gp43 tratada observamos baixos níveis de IL-12, IFN- $\gamma$ e IL-10 em PBMC de indivíduos curados, com discreto aumento dessas citocinas no grupo de indivíduos com a doença ativa, porém sem aumento significativo em relação ao basal (células sem estímulo), corroborando os dados de linfoproliferação de baixa capacidade de estimular a resposta imune pela gp43 tratada.

Os resultados obtidos com os indivíduos sadios mostraram baixos níveis de secreção de IL-10, IL-12 e IFN-g, mesmo com o filtrado de cultura livre de gp43, apesar deste induzir uma discreta, porém significante resposta linfoproliferativa. Esses resultados negativos já eram previstos para a gp43, e corroboram estudos já realizados por nosso e outros grupo (BENARD et al.2001; ROMANO et al. 2002; IWAI et al. 2007; SADAHIRO et al. 2007), e para a gp43 tratada com metaperiodato, já que esse antígeno foi utilizado por outros autores a fim de remover ou pelo menos diminuir a reatividade cruzada com outros fungos. Entretanto, com o filtrado de cultura livre de gp43, pelas suas características, esperávamos que este induzisse uma resposta inespecífica mais intensa. Talvez esse resultado possa ser explicado pela baixa concentração de cada um destes componentes do filtrado, proteínas, lipídeos e/ou glicoproteínas, como discutido anteriormente.

Os dados de citocinas são condizentes com os resultados de linfoproliferação, mostrando que com o estímulo de filtrado de cultura houve uma menor proliferação de PBMC tanto no grupo de indivíduos curados quanto no grupo de indivíduos com a doença ativa, possivelmente relacionada aos altos níveis de IL-10 induzidos, o que não ocorreu com o estímulo de gp43 no grupo de indivíduos curados, em que verificamos proliferação significante provavelmente pela indução de IL-12 e IFN- $\gamma$ e ausência de secreção de IL-10. 


\section{7-CONCLUSÕES}

Os dados observados principalmente no grupo de indivíduos curados reforçam o papel da gp43 como glicoproteína importante na ativação da resposta imune celular na PCM.

O filtrado de cultura livre de gp43 também apresentou capacidade de estimular linfócitos in vitro desses indivíduos, porém em menor intensidade que a gp43. Além disso, demonstramos que a anergia dos linfócitos T observada nos pacientes com doença ativa não é restrita à gp43, pois também não observamos resposta com o filtrado de cultura nestes indivíduos, ao mesmo tempo em que estes mantinham a capacidade de responder ao antígeno de $C$. albicans. Porém este filtrado devido as suas características de complexa mistura antigênica induz resposta inespecífica.

Podemos concluir também que a gp43 tratada com metaperiodato não é apropriada para ensaios de imunidade celular, pois não induziu nenhum tipo de resposta.

Com relação à secreção de citocinas, a gp43 induziu produção de citocinas de padrão Th1, provavelmente correspondendo a imunidade protetora nesta micose, o mesmo não ocorreu com o filtrado de cultura. 


\section{8- REFERÊNCIAS BIBLIOGRÁGICAS}

1. ALBUQUERQUE CF, DA SILVA SH, CAMARGO ZP. Improvement of the specificity of na enzyme-linked immunosorbent assay for diagnosis of paracoccidioidomycosis. J Clin Microbiol. 2005; 43(4):1944-6.

2. ALHEIM M, LAZDINA U, MILICH D.R, SÄLLBERG M. Flow cytometric determination of cytokine production and proliferation in hepatitis B core antigen specific murine CD4 cells: lack of correlation between number of cytokine producing cells and cytokine levels in supernatant. J Immunol Methods. 2001; $1 ; 258(1-2): 157-67$.

3. ALMEIDA F P. Estudos comparativos do granuloma coccidiótico nos Estados Unidos e no Brasil: novo gênero para o parasito brasileiro. An Fac Med S. Paulo.1930;5:125-41.

4. ALMEIDA SR, LOPES JD. The low efficiency of dendritic cells and macrophages from mice susceptible to Paracoccidioides brasiliensis in inducing a Th1 response. Braz J Med Biol Res 2001;34(4):529-37.

5. BAGAGLI E, SANO A, COELHO KI, ALQUATI S, MIYAJI M, DE CAMARGO $\mathrm{ZP}$, et al. Isolation of Paracoccidioides brasiliensis from armadillos (Dasypus noveminctus) captured in an endemic area of paracoccidioidomycosis. Am J Trop Med Hyg 1998;58(4):505-12.

6. BARBOSA W, DAHER R.R. Blastomicose Sul-Americana (Paracoccidioidomicose). In: VERONESI R. Doenças infecciosas e parasitárias. P. 638-651. Rio de Janeiro, 1982. 
7. BENARD G, DURANDY A, ASSIS CM, HONG MA, ORII NM, SATO MN, MENDES-GIANINI MJ, LACAZ CS, DUARTE AJ. Responses of T and B lymphocytes to a Paracoccidioides brasiliensis cell wall extract in healthy sensitized and nonsensitized subjects. Am J Trop Med Hyg. 1995 Aug;53(2):18994.

8. BENARD G, HONG MA, DEL NEGRO GM, BATISTA L, SHIKANAIYASUDA MA, DUARTE AJ. Antigen-specific immunosuppression in paracoccidioidomycosis. Am J Trop Med Hyg 1996;54(1):7-12.

9. BENARD G, MENDES-GIANNINI MJ, JUVENALE M, MIRANDA ET, DUARTE AJ. Immunosuppression in paracoccidioidomycosis: $\mathrm{T}$ cell hyporesponsiveness to two Paracoccidioides brasiliensis glycoproteins that elicit strong humoral immune response. J Infect Dis 1997;175(5):1263-7.

10. BENARD G, ROMANO C, CACERE C, JUVENALE M, MENDES-GIANNINI M.J., DUARTE A. Imbalance of IL-2, IFN $\gamma$ and IL-10 secretion in the immunosuppression associated with human paracoccidioidomycosis. Cytokine. $2001 \mathrm{Feb} 21 ; 13(4): 248-52$

11. BIALEK R, IBRICEVIC A, AEPINUS C, NAJVAR LK, FOTHERGILL AW, KNOBLOCH J, GRAYBILL JR. Detection of Paracoccidioides brasiliensis in tissue samples by a nested PCR assay. J Clin Microbiol. 2000;38(8):2940-2.

12. BLOTTA MH, MAMONI RL, OLIVEIRA SJ, NOUER AS, PAPAIODANOU PM, GOUVEIA A, CAMARGO ZP.. Endemic regions of paracoccidioidomycosis in Brazil: a clinical and epidemiologic study of 584 cases in the southeast region. Am J Trop Med Hyg. 1999;61(3):390-4. 
13. BLOTTA MHS, CAMARGO ZP. Immunological response to cell-free antigens of Paracoccidioides brasiliensis: relationship with clinical forms of paracoccidioidomycosis. J Clin Microbiol. 1993;31(3):671-6.

14. BORGES-WALMSLEY MI, CHEN D, SHU X, WALMSLEY AR. The pathobiology of Paracoccidioides brasiliensis. Trends Microbiol 2002;10(2):80-7.

15. BUENO JP, MENDES-GIANNINI MJ, DEL NEGRO GM, ASSIS CM, TAKIGUTI CK, SHIKANAI-YASUDA MA. IgG, IgM and IgA antibody response for the diagnosis and follow-up of paracoccidioidomycosis: comparison of counterimmunoelectrophoresis and complement fixation. J Med Vet Mycol. $1997 ; 35(3): 213-7$.

16. CACERE CR, ROMANO CC, MENDES-GIANNINI MJ, DUARTE AJ, BENARD G. The role of apoptosis in the antigen-specific $T$ cell hyporesponsivenes of paracoccidioidomycosis patients. Clin Immunol. 2002 Nov; 105(2):215-22

17. CADAVID D, RESTREPO A. Factors associated with Paracoccidiodes brasiliensis infection among permanent residents of three endemic areas in Colombia. Epidemiol Infect 1993;111(1):121-33.

18. CALICH VL, KASHINO SS. Cytokines produced by susceptible and resistant mice in the course of Paracoccidioides brasiliensis infection. Braz J Med Biol Res 1998;31(5):615-23.

19. CALlE D, ROSERO DS, OROZCO LC, CAMARGO D, CASTANEDA E, RESTREPO A. Paracoccidioidomycosis in Colombia: an ecological study. Epidemiol Infect. 2001;126(2):309-15. 
20. CAMPO-AASEN I, DE CABRAL N, YARZÁBAL L. Sub-cellular localization of antigen E/2 of Paracoccidioides brasiliensis. $\mathrm{Na}$ immunoenzymatic electron microscopy study. Sabouraudia. 1980 Sep; 18(3):167-71

21. CARBOMELL LM, KANETSUNA F, GIL F. Chemical morphology of glucan and chitin in the cell wall of the yeast phase of Paracoccidioides brasiliensis. J. Bacteriol, 1970 Feb; 101(2):636-42

22. CARBONELL, L.M.; CASTEJON, H \&POLLAK, L. Cytochemistry of Paracoccidioides brasiliensis. I. Cytochemistry of cytoplasmic polysaccharides in yeast form cultures with light microscope. 1964. J. Histochem. Cytohem., 12:413418.

23. COLTRI KC, CASABONA-FORTUNATO AS, GENNARI-CARDOSO ML, PINZAN CF, RUAS LP, MARIANO VS, MARTINEZ R, ROSA JC, PANUNTOCASTELO A, ROQUE-BARREIRA MC. Paracoccin, a GlcNAc-binding lectin from Paracoccidioides brasiliensis, binds to laminin and induces TNF-alpha production by macrophages. Microbes Infect. 2006 Mar;8(3):704-13. Epub 2006 Jan 17.

24. CONTI-DÍAZ IA, SOMMA-MOREIRA RE, GEZUELE E, DE GIMÉNEZ AC, PENA MI, MACKINNON JE. Immunoeletroosmophoresis-immunodiffusion in paracoccidioidomycosis. Sabouraudia. 1973 mar; 11(1):39-41

25. COUTINHO ZF, SILVA D, LAZERA M, PETRI V, OLIVEIRA RM, SABROZA PC, et al. Paracoccidioidomycosis mortality in Brazil (1980-1995). Cad. Saúde Pública. 2002;18 (5):1441-54

26. De ALBORNOZ MB. Isolation of Paracoccidioides brasiliensis from rural soil in Venezuela. Sabouraudia 1971;9(3):248-53. 
27. DEL NEGRO GMB, LACAZ CS, ZAMITH VA, SIQUEIRA AM. General and clinical aspects: polar forms of Paracoccidoidomycosis, the disease in childhood. In: FRANCO M, LACAZ CS, RESTREPO A. DEL NEGRO G. Paracoccidioidomycosis. CRC Press, Boca Raton, Flórida, USA, 1994.

28. DINIZ SN, CISALPINO PS, FREIRE AT, SILVA-TEIXEIRA DN, CONTIGLI C, RODRIGUES JÚNIOR V, GOES AM.In vitro granuloma formation, NO production and cytokines profile from human mononuclear cells induced by fractionated antigens of Paracoccidioides brasiliensis. Hum Immunol. 2001 Aug;62(8):799-808.

29. DOS SANTOS WA, DA SILVA BM, PASSOS ED, ZANDONADE E, FALQUETO A. Association between smoking and paracoccidioidomycosis: a case-control study in the State of Espírito Santo, Brazil.Cad Saude Publica. 2003 Jan-Feb;19(1):245-53. Epub 2003 Apr 1.

30. FAGUNDES R. Pesquisa da paracoccidioidomicose em cães (Canis familiaris) na região endêmica de Botucatu, São Paulo [Dissertação de Mestrado]. Botucatu: Faculdade de Medicina Veterinária e Zootecnia de Botucatu; 2002.

31. FAVA NETTO C. Estudos quantitativos sobre a fixação do complemento na blastomicose sul-americana, com antígeno polissacarídeo. Arq Cir Clin Exp. $1955 ; 18: 197-254$.

32. FAVA NETTO C, VEGAS VS, SCIAMMAMÉA IM, GUARNIERI DB. Antígeno polissacarídeo do Paracoccidoides brasiliensis. Estudo do tempo de cultivo do Paracoccidoides brasiliensis, necessário ao preparo do antígeno. Rev Inst Adolfo Lutz. 1969;11:177-81. 
33. FAVA-NETTO C. Contribuição para o estudo imunológico da blastomicose de Lutz. Rev Inst Adolfo Lutz. 1961;21:99-194.

34. FERREIRA MS, FREITAS LH, LACAZ CS, DEL NEGRO GM, MELO NT, GARCIA NM, ASSIS CM, SALEBIAN A, HEINS-VACCARI EM. Isolation and characterization of a Paracoccidioides brasiliensis strain from a dogfood probably contaminated with soil in Uberlandia, Brazil. J Med Vet Mycol. 1990;28(3):253-6.

35. FERREIRA-DA-CRUZ MF, FRANCESCONI-DO VALE AC, ESPINERA MC, WAMKE B, GALVÃO CASTRO BO. Study of antibodies in paracoccidioidomycosis: follow-up of patients during and after treatment. J Med Vet Mycol. 1990;28(2):151-7.

36. FERRI RG. Estudo imunoquímico de antígenos intracelulares. Hospital. 1961;59:917-24.

37. FIGUEIREDO F, SILVA CL, ALVES LMC, ROSSII MA. Participation of Paracoccidioides brasiliensis lipids and polysacharides in the evaluation of granulomas. Braz J Med Biol Res. 1986;19:615.

38. FORJAZ MH, FISCHMAN O, DE CAMARGO ZP, VIEIRA FILHO JP, COLOMBO AL. [Paracoccidioidomycosis in Brazilian Indians of the Surui tribe: clinical-laboratory study of 2 cases]. Rev Soc Bras Med Trop 1999;32(5):571-5.

39. FRANCO M. Host-parasite relationships in paracoccidioidomycosis. J Med Vet Mycol. 1986;25:5-18.

40. FRANCO M, BAGAGLI E, SCAPOLIO S, LACAZ CS A critical analysis of isolation of Paracoccidioides brasiliensis from soil. Med Mycol. 2000;38(3):18591. 
41. FRANCO M, MONTENEGRO MR, MENDES RP, MARQUES SA, DILLON NL, MOTA NG. Paracoccidioidomycosis: a recently proposed classification of this clinical forms. Rev Soc Bras Med Trop. 1987;20(2):129-32.

42. GARCIA NM, DEL NEGRO GM, HEINS-VACCARI EM, DE MELO NT, DE ASSIS CM, LACAZ CDA S. [Paracoccidioides brasiliensis, a new sample isolated from feces of a penguin (Pygoscelis adeliae)]. Rev Inst Med Trop Sao Paulo 1993;35(3):227-35.

43. GINARTE M, PEREIRO M, JR., TORIBIO J. Imported paracoccidioidomycosis in Spain. Mycoses 2003;46(9-10):407-11.

44. GONZÁLES-OCHOA A. Classificacion clinica de las micoses. Rev Int Salubr Enferm Trop. 1956;16:1.

45. GROSSE E, Tamsitt J. Paracoccidioides brasiliensis recovered from the intestinal tract of three bats (Artibeus lituratus) in Colombia S.A. Sabouraudia. 1965;4:12425.

46. GUEZELLE E. Aislamiento de Paracoccidioides sp. de heces de pinguino de la Antártida, res. B2. In: Resúmenes IV Encuentro Internacional sobre Paracoccidioidomicosis; 1989; Caracas, Venezuela.

47. HELDER BARBOSA F, MONTENEGRO MR, BAGAGLI E. Virulence profiles of ten Paracoccidioides brasiliensis isolates obtained from armadillos (Dasypus novemcinctus). Med Mycol. 2003;41:89-96.

48. IWAI LK, YOSHIDA M, SADAHIRO A, DA SILVA WR, MARIN ML, GOLDBERG AC, JULIANO MA, JULIANO L, SHIKANAI-YASUDA MA, KALIL J, CUNHA-NETO E, TRAVASSOS LR. T-cell recognition of Paracoccidioides brasiliensis gp43-derived peptides in patients with 
paracoccidioidomycosis and healthy individuals.Clin Vaccine Immunol. 2007 Apr;14(4):474-6.

49. KANETSUNA, F \& CARBONELL, L.M. Enzymes in glycolysis and the citric acis cycle in the yeast and mycelial forms of Paracoccidioides brasiliensis. 1966. J. Bact. 92:1.315-1.320

50. KARHAWI AS, COLOMBO AL, SALOMÃO R. Production of IFN-gamma is impaired in patients with paracoccidioidomycosis during active disease and is restored after clinical remission. Med Mycol. 2000 Jun;38(3):225-9.

51. KUROKAWA CS, ARAUJO JP JR, SOARES AM, SUGIZAKI MF, PERAÇOLI MT. Pro- and anti-inflammatory cytokines produced by human monocytes challenged in vitro with Paracoccidioides brasiliensis. Microbiol Immunol. 2007;51(4):421-8.

52. KUROKAWA CS, SUGIZAKI MF, PERACOLI MT. Virulence factors in fungi of systemic mycoses. Rev Inst Med Trop Sao Paulo 1998;40(3):125-35.

53. LACAZ C S. Evolução dos conhecimentos sobre a paracoccidioidomicose. Um pouco de sua hitória. In: DEL NEGRO G., LACAZ C S., FIORILLO A M., Paracoccidioidomicose, Blastomicose sul-americana. P. 1-21. São Paulo, 1982.

54. LACAZ C S. Paracoccidioidomicose. In: LACAZ C S, PORTO E, MARTINS JEC, HEINS-VACCARI E, MELO NT. Tratado de Micologia Médica Lacaz. São Paulo: Sarvier; 2002.

55. LACAZ CS. Paracoccidioides brasiliensis: Morphology; Evolutionary Cycle; Maitenance during Saprophytic Life; Biology; Virulence; Taxonom. In: FRANCO MF, LACAZ CS, RESTREPO A, DEL NEGRO G. Paracoccidioidomycosis. CRC Press, Boca Raton, USA. 1994. 
56. LACAZ CS. Novos dados em relação a blastomicose sul-americana e seu agente etiológico. Rev Med Cir S. Paulo. 1949;IX:59-96.

57. LACAZ CS, PASSOS FILHO MCR, FAVA NETTO C, MACARRON R. Contribuição para o estudo da Blastomicose-infecção: inquérito com paracoccidioidina. Estudo sorológico e clínico radiológico dos paracoccidioidinospositivos. Rev Inst Med Trop São Paulo. 1959;1:245-59.

58. LONDERO A T. Epidemiologia. In DEL NEGRO G., LACAZ C S., FIORILLO A M., Paracoccidioidomicose, Blastomicose sul-americana. P. 85-90. São Paulo, 1982.

59. LONDERO AT, DEL NEGRO G. Paracoccidioidomicose. J Pneumol. 1986;12:4160.

60. LOPES JD, MOURA-CAMPOS MC, VICENTINI AP, GESZTESI JL, DE SOUZA W, CAMARGO ZP. Characterization of glycoprotein gp43, the major laminin-binding protein of Paracoccidioides brasiliensis. Braz J Med Biol Res. 1994;27(9):2309-13.

61. LOPEZ RC, RESTREPO A. Spontaneous regression of pulmonary paracoccidioidomycosis. Mycopathol. 1983;83:187-9.

62. LUTZ A. Uma mycose pseudococcidica localisada na bocca e observada no Brazil. Contribuição ao conhecimento das hyphoblastomicoses americanas. Brazil Médico. 1908;13:121-24.

63. LUTZ A. Uma mycose pseudococcidica localisada na bocca e observada no Brazil. Contribuição ao conhecimento das hyphoblastomicoses americanas. Brazil Médico. 1908;15:141-44. 
64. MARQUES SA, FRANCO MF, MENDES RP, SILVA NC, BACCILI C, CURCELLI ED, et al. Epidemiologic aspects of paracoccidioidomycosis in the endemic area of Botucatu (São Paulo - Brazil). Rev Inst Med Trop São Paulo. $1983 ; 25(2): 87-92$.

65. MARTINEZ R, MOYA MJ. [The relationship between paracoccidioidomycosis and alcoholism]. Rev Saude Publica 1992;26(1):12-6.

66. MARTINEZ R, VITALI LH, HENRIQUES JH, MACHADO AA, ALBERNAZ A, LIMA AA. [Seroepidemiological survey for infections by fungi causing systemic mycoses in the Xacriaba Indian Reserve, Minas Gerais State, Brazil]. Rev Soc Bras Med Trop 2002;35(4):347-50.

67. MENDES RP. The Gamut of clinical manifestation. In: FRANCO M, LACAZ CS, RESTREPO A. DEL NEGRO G. Paracoccidioidomycosis. CRC Press, Boca Raton, Flórida, USA, 1994.

68. MENDES-GIANNINI MJ, CAMARGO ME, LACAZ CS, FERREIRA AW. Immunoenzymatic absorption test for serodiagnosis of paracoccidioidomycosis. $\mathbf{J}$ Clin Microbiol. 1984;20(1):103-8.

69. MENDES-GIANNINI MJ, MORAES RA, RICCI TA.Proteolytic activity of the 43,000 molecular weight antigen secreted by Paracoccidioides brasiliensis. Rev Inst Med Trop Sao Paulo. 1990 Sep-Oct;32(5):384-5.

70. MENDES-GIANNINI MJ, TAYLOR ML, BOUCHARA JB, BURGER E, CALICH VL, ESCALANTE ED, et al. Pathogenesis II: fungal responses to host responses: interaction of host cells with fungi. Med Mycol 2000;38 Suppl 1:11323. 
71. MENDES-GIANNINI MJS, BUENO JP, SHIKANAI-YASUDA MA, FERREIRA AW, MASUDA A. Detection of the 43,000-molecular-weight glycoprotein in sera of patients with paracoccidioidomycosis. J Clin Microbiol. 1989;27(12):2842-5.

72. MOSES A. Fixação de complemento na blastomicose. Mem Inst Oswaldo Cruz. 1916;8:68-70.

73. MOTA NG, REZKALLAH-IWASSO MT, PERAÇOLI MT, AUDI RC, MENDES RP, MARCONDES J, MARQUES SA, DILLON NL, FRANCO MF.Correlation between cell-mediated immunity and clinical forms of paracoccidioidomycosis. Trans R Soc Trop Med Hyg. 1985;79(6):765-72.

74. MOTTA LC. Granulomatose paracoccidioica. An Fac Med São Paulo. $1935 ; 11: 293$.

75. MUSATTI CC, REZKALLAH MT, MENDES E, MENDES NF. In vivo and in vitro evaluation of cell-mediated immunity in patients with paracoccidiodomycosis. Cell Immunol. 1976 Jun 15;24(2):365-78.

76. NAIFF R, BARRETTO T. Novos registros de Paracoccidioides brasiliensis em tatus (Dasypus novemcinctus). In: Proceedings Congreso Brasileiro Parasitología; 1989; Rio de Janeiro, Brazil: Sociedade Brasileira de Parasitologia. Abstract 197.

77. NAIFF RD, FERREIRA LC, BARRET TV, NAIFF MF, ARIAS JR. Enzootic paracoccidioidomycosis in armadillos (Dasypus novemcinctus) in the State of Para. Rev Inst Med Trop Sao Paulo. 1986;28(1):19-27.

78. NEGRONI P. [The Paracoccidioides brasiliensis lives saprophytically in the soil of Argentina]. Prensa Med Argent 1966;53(39):2381-2. 
79. NEGRONI, R.; ELIAS COSTA, M.R.I.; DE BIANCHI, O. \& GALIMBERTI, R. Preparación y studio de un antígeno celular de Paracoccidioides brasiliensis útl para pruebas cutáneas. Sabouraudia. 1976. 14:265-273

80. OLIVEIRA SJ, MAMONI RL, MUSATTI CC, PAPAIORDANOU PM, BLOTTA MH. Cytokines and lymphocyte proliferation in juvenile and adult forms of paracoccidioidomycosis: comparison with infected and non-infected controls. Microbes Infect 2002;4(2):139-44.

81. ONO MA, BRACARENSE APFRL, MORAIS HAS, TRAPP SM, BELITARDO DR. Canine paracoccidioidomycosis: a seroepidemiologic study. Med Mycol. 2001;39(3):277-82.

82. ONO MA, ITANO EN, MIZUNO LT, MIZUNO EHF, CAMARGO ZP. Inhibition of Paracoccidioides brasiliensis by pesticides: is this a partial explanation for the difficulty in isolating this fungus from the soil? Med Mycol. 2002;40(5):493-9.

83. ONO MA, KISHIMA MO, ITANO EN, BRACARENSE AP, CAMARGO ZP. Experimental paracoccidioidomycosis in dogs. Med Mycol 2003;41(3):265-8.

84. PANIAGO AM, AGUIAR JI, AGUIAR ES, DA CUNHA RV, PEREIRA GR, LONDERO AT, et al. [Paracoccidioidomycosis: a clinical and epidemiological study of 422 cases observed in Mato Grosso do Sul]. Rev Soc Bras Med Trop 2003;36(4):455-9.

85. PANUNTO-CASTELO A, FREITAS-DA-SILVA G, BRAGHETO IC, MARTINEZ R, ROQUE-BARREIRA MC. Paracoccidioides brasiliensis exoantigens: recognition by $\operatorname{IgG}$ from patients with different clinical forms of paracoccidioidomycosis. Microbes Infect 2003;5(13):1205-11. 
86. PERAÇOLI MT, KUROKAWA CS, CALVI SA, MENDES RP, PEREIRA PC, MARQUES SA, SOARES AM. Production of pro- and anti-inflammatory cytokines by monocytes from patients with paracoccidioidomycosis. Microbes Infect. $2003 \mathrm{Apr} ; 5(5): 413-8$

87. PEREIRA RM, TRESOLDI AT, DA SILVA MT, BUCARETCHI F. Fatal disseminated paracoccidioidomycosis in a two-year-old child. Rev Inst Med Trop Sao Paulo 2004;46(1):37-9.

88. PUCCIA R, SCHENKMAN S, GORIN PA, TRAVASSOS LR. Exocellular components of Paracoccidioides brasiliensis: identification of a specific antigen. Infect Immun 1986;53(1):199-206.

89. PUCCIA R, TRAVASSOS LR. The 43-kDa glycoprotein from the human pathogen Paracoccidioides brasiliensis and its deglycosylated form: excretion and susceptibility to proteolysis. Arch Biochem Biophys. 1991 Sep; 289(2):298-302

90. PUCCIA R, TRAVASSOS LR. 43-kilodalton glycoprotein from Paracoccidioides brasiliensis: immunochemical reactions with sera from patients with paracoccidioidomycosis, histoplasmosis, or Jorge Lobo's disease. J Clin Microbiol. 1991;29(8):1610-5.

91. RESTREPO A. The ecology of Paracoccidioides brasiliensis: a puzzle still unsolved. Sabouraudia 1985;23(5):323-34.

92. RESTREPO A, CANO LE, TABARES AM. A comparison of mycelial filtrate and yeast lysate-paracoccidioidin in patients with paracoccidioidomycosis. Mycopathol. 1983;84(1):49-54. 
93. RESTREPO A, DROUHET E, Study of precipitating antibodies in South American blastomycosis by immunoelectrophoretic analysis of Paracoccidiodes brasiliensis antigens.Ann Inst Pasteur 1970 Sep;119(3):338-46.

94. RESTREPO A, MCEWEN JG, CASTANEDA E. The habitat of Paracoccidioides brasiliensis: how far from solving the riddle? Med Mycol. 2001;39(3):233-41.

95. RESTREPO, A. \& MONCADA, L.H. Characterisation of the precipitin bands detected in the immunodiffusion test for paracoccidioidomycosis. 1974. Appl. Microbiol. 28:138-144

96. RICCI G, MOTA FT., WAKAMATSU A, SERAFIM RC, BORRA RC, FRANCO, M. Canine paracoccidioidomycosis. Med Mycol. 2004;42:379-83.

97. ROMANO CC, MENDES-GIANNINI MJ, DUARTE AJ, BENARD G. The role of interleukin-10 in the differential expression of interleukin-12p70 and its beta2 receptor on patients with active or treated paracoccidioidomycosis and healthy infected subjects. Clin Immunol. 2005 Jan;114(1):86-94

98. ROMANO CC, MENDES-GIANNINI MJ, DUARTE AJ, BENARD G. IL-12 and neutralization of endogenous IL-10 revert the in vitro antigen-specific cellular immunosuppression of paracoccidioidomycosis patients. Cytokine 2002;18(3):14957.

99. SADAHIRO A, DIOGO CL, OSHIRO TM, SHIKANAI-YASUDA MA.Kinetics of IFN-gamma, TNF-alpha, IL-10 and IL-4 production by mononuclear cells stimulated with gp43 peptides, in patients cured of paracoccidioidomycosis.Rev Soc Bras Med Trop. 2007 Mar-Apr;40(2):156-62.

100. SAN-BLAS G. The cell wall of fungal human pathogens: its possible role in hostparasite relationship. Mycopathol. 1982;79(3):159-84. 
101. SAN-BLAS G, NINO-VEGA G, ITURRIAGA T. Paracoccidioides brasiliensis and paracoccidioidomycosis: molecular approaches to morphogenesis, diagnosis, epidemiology, taxonomy and genetics. Med Mycol. 2002;40(3):225-42.

102. SAN-BLAS G, SAN-BLAS F. Molecular aspects of dimorphism. Crit Rev Microbiol. 1984;11(2):101-27.

103. SAN-BLAS G, SAN-BLAS F. Paracoccidioides brasiliensis: cell wall structure and virulence. Mycopathol. 1977;62(2):77-86.

104. SAN-BLAS G, SAN-BLAS F. Molecular aspects of dimorphism. Crit Rev Microbiol.1984;11(2):101-27.

105. SHOME SK, BATISTA AC. Ocurrence of Paracoccidioides brasiliensis in the soil of Recife, Brazil. Rev Fac Med Fed Ceará. 1963;3:90-4.

106. SILVA DF. Análise da estabilidade de exaontígenos de Paracoccidioides brasiliensis. [Dissertação de Mestrado]. São Paulo: Coordenadoria de Controle de Doenças; 2005, p.169.

107. SILVA-VERGARA ML, MARTINEZ R. Role of the aramdillo Dasypus novemcinctus in the epidemiology of paracoccidioidomycosis. Mycopathologia. 1999;144:131-33.

108. SILVA-VERGARA ML, MARTINEZ R, CAMARGO ZP, MALTA MH, MAFFEI CM, CHADU JB. Isolation of Paracoccidioides brasiliensis from armadillos (Dasypus novemcinctus) in an area where the fungus was recently isolated from soil. Med Mycol 2000;38(3):193-9.

109. SILVA-VERGARA ML, MARTINEZ R, CHADU A, MADEIRA M, FREITASSILVA-G, LEITE MAFFEI CM. Isolation of a Paracoccidioides brasiliensis strain 
from the soil of a coffee plantation in Ibiá, State of Minas Gerias, Brazil. Med Mycol. 1998;36(1):37-42.

110. SIQUEIRA AM. Avaliação da sensibilidade e especificidade de algumas provas sorológicas no diagnóstico, prognóstico e controle de cura da paracoccidioidomicose. Caracterização do antígeno $\mathrm{E}_{2}$ de Paracoccidioides brasiliensis. [Tese de Doutorado]. São Paulo: Universidade de São Paulo; 1982.

111. TABORDA CP, JULIANO MA, PUCCIA R, FRANCO M, TRAVASSOS LR. Mapping of the T-cell epitope in the major 43-kilodalton glycoprotein of Paracoccidioides brasiliensis which induces a Th-1 response protective against fungal infection in BALB/c mice. Infect Immun 1998;66(2):786-93.

112. TABORDA, CP, CAMARGO ZP. Diagnosis of paracoccidioidomycosis by dot immunobinding assay for antibody detection using the purified and specific antigen gp43. J Clin Microbiol. 1994 Feb; 32(2):554-6

113. TERÇARIOLI GR, BAGAGLI E, REIS GM, THEODORO RC, BOSCO S, MACORIS AS, RICHINI-PEREIRA VB. Ecological study of Paracoccidioides brasiliensis in soil: growth ability, conidia production and molecular detection. BMC Microbiol. 2007;22:7:92.

114. YARZABAL LA, BOUT D, NAQUIRA F, FRUIT J, ANDRIEU S. Identification and purification of the specific antigen of Paracoccidioides brasiliensis responsible for immunoelectrophoretic band E. Sabouraudia 1977;15(1):79-85.

115. YARZABAL LA, DE ALBORNOZ MB, DE CABRAL NA, SANTIAGO AR. Specific double diffusion microtechinique for the diagnosis of aspergillosis and paracoccidioidomycosis using monospecific antisera. Sabouraudia. 1978;16(1):5562. 